\title{
Application of ionic liquids in thermosetting polymers: Epoxy and cyanate ester resins
}

\author{
A. Vashchuk ${ }^{1,2}$, A. M. Fainleib ${ }^{1 *}$, O. Starostenko ${ }^{1}$, D. Grande ${ }^{2}$ \\ ${ }^{1}$ Institute of Macromolecular Chemistry, National Academy of Sciences of Ukraine, Kharkivske shose 48, 02160 Kyiv, \\ Ukraine \\ ${ }^{2}$ Institut de Chimie et des Matériaux Paris-Est, UMR 7182 CNRS - Université Paris-Est Créteil Val-de-Marne, \\ 2 rue Henri Dunant, 94320 Thiais, France
}

Received 27 March 2018; accepted in revised form 16 May 2018

\begin{abstract}
Thermosetting polymers are widely used as industrial materials due to good heat resistance, dimensional stability and chemical resistance. There is a longstanding and widespread interest in designing novel polymer networks, and utilization of ionic liquids (ILs) opens up new frontiers to meet this challenge by creating new materials. For thermosetting polymers, ILs offer many advantages, either as catalytic agents, plasticizers, conducting additives, or porogens. Furthermore, ILs show rich structural diversity and can be incorporated into a polymer matrix to achieve better final properties. This review emphasizes the urgent need for understanding the role, efficiency and perspectives of an innovative class of components, namely ILs with the potential to impact across many areas of thermosetting polymers. To avoid ambiguity and make the review selfreading, basic ideas about the application of ILs in thermosetting polymers are first outlined.
\end{abstract}

Keywords: thermosetting resins, epoxy resins, cyanate ester resins, ionic liquids

\section{Introduction}

Ionic liquids (ILs) are the subject of widespread interest as alternatives to conventional organic solvents due to their very special properties, including recycling ability. Many known ILs are commercially available from several suppliers. Ideally, ILs are nonflammable, optically clear and are relatively inexpensive to manufacture [1]. Many ILs exhibit a wide temperature range of liquid state up to about $300^{\circ} \mathrm{C}$, providing the opportunity to carry out high-temperature reactions. Being composed entirely of ions, these novel multifunctional agents so called as «designer solvents» have extremely low vapour pressure and low volatility. As a result of one or more of these characteristic properties, ILs have already been found useful in the polymer chemistry for diverse applications [2-5]. ILs make an increasing impact in the field of cross-linked polymers, in particular on the development of thermosetting polymers and composite materials with various interesting properties [6-12]. All these applications require a strong confinement of the ionic liquid within the polymer network with no exudation of the ILs.

In this way, herein, we are going to review the using of ILs for a wide range of applications in thermoset materials that could be important hosts for ILs. The application of ILs in thermosets has quickly advanced from using them as a reaction media to application as functional additives. Certainly, innovation in this field requires the control of their structure at nanoscale and addition of ILs can be a new and facile method to manage the morphology and properties of thermoset polymers as well as to widen their application. 


\section{Ionic liquids}

ILs may be considered as a class of salts with a melting temperature below $100^{\circ} \mathrm{C}$. The story of ILs begins with the first report of the preparation of ethylammonium nitrate salt using the reaction of ethylamine with nitric acid having melting point of $12^{\circ} \mathrm{C}$ in 1914 [13]:

$\mathrm{EtNH}_{2}+\mathrm{HNO}_{3}=\left[\mathrm{EtNH}_{4}\right]+\left[\mathrm{NO}_{3}\right]^{-}$

Despite this the interest have developed after the discovery of binary ILs made from mixtures of aluminum (III) chlorides and $N$-alkylpyridinium [14] or 1,3-dialkylimidazolium chlorides [15]. Nevertheless, a major drawback of all chloroaluminate (III) ILs, their moisture sensitivity remained unresolved. In particular, Wilkes and Zawarotko [16] prepared and characterized the air and water stable 1-ethyl-3methylimidazolium ILs with different anions.

Over the last two decades a large variety of ILs have been investigated marked by an exponential growth in a number of publications represented by the yearly increase starting from near 10 in 1990 to more than 7000 papers published last year (Figure 1). The first publications on using ILs in polymers have appeared in 2002 and then increased quickly in the last two decades and a summary on their applications and properties may be found in a number of review articles [17-23] and book [24]. There is no doubt that this area of research has been an important point of polymer chemistry as well.

ILs are self-dissociated and do not need a solvent to dissociate into cations and anions that uniquely

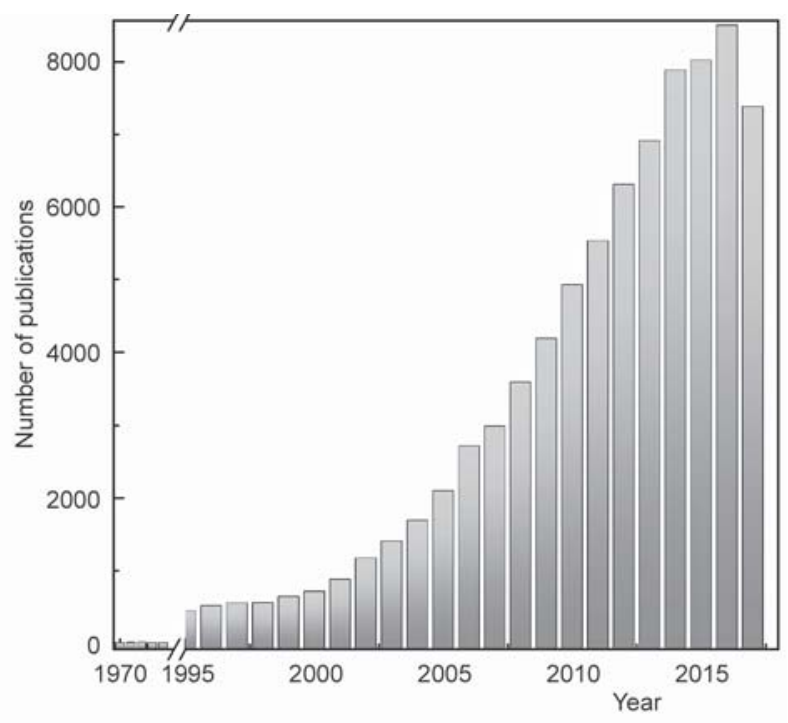

Figure 1. Publications on ILs as determined from the ISI Web of Science ${ }^{\circledR}$ (on December 12, 2017).

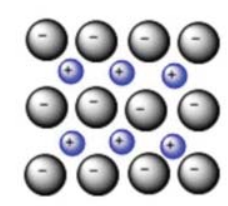

Molten salt

- Hight melting point

- Hight viscous medium
- Liquid at temperatures $<100^{\circ} \mathrm{C}$ - Low viscous medium

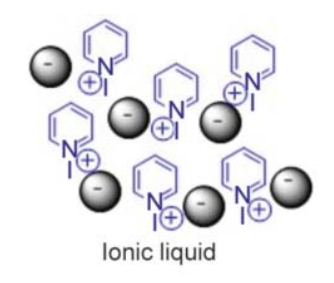

Figure 2. Schematical image of ionic structure of molten salt and IL.

distinguish them from classical salts like $\mathrm{NaCl}, \mathrm{KBr}$. What is the difference between a molten salt and an IL? Both molten salts and ILs are liquid salts containing only ions (Figure 2). However, in molten salts, there are symmetric cations and anions making the lattice well packed and hence it requires a large energy to break the lattice. Contrary to molten salts, IL cations have irregular shape preventing crystal packing [25-27]. Therefore, molten salts melt above $100^{\circ} \mathrm{C}\left(T_{\text {melt NaCl}}=801{ }^{\circ} \mathrm{C}, T_{\text {melt KCl }}=770^{\circ} \mathrm{C}\right)$, and ILs melt much below that temperature (in particular, Room temperature ILs (RTIL) are liquid already at an ambient temperature).

The most common classes of cations and anions are illustrated in Figure 3. The structural design of ILs is playing a very important role as the major properties may be easily controlled by changing the combinations of cation and anion types $\left(10^{18}\right.$ potential structures [28]). In this way, their properties can be varied dramatically by the creation of unique combinations of cations, anions and chains lengths. The change of anion can drastically affect physical properties of ILs such as hydrophilicity, viscosity and melting point as well as thermal stability. On the basis of reported data, the relative thermal stability $\left(T_{\text {onset }}\left[{ }^{\circ} \mathrm{C}\right]\right)$ of imidazolium IL, i.e. $\left[\mathrm{C}_{2} \mathrm{MIm}\right]$ containing some common anions decreases in the following order: $\left[\mathrm{C}(\mathrm{CN})_{3}\right]^{-} \approx\left[\mathrm{BF}_{4}\right]^{-}\left(450^{\circ} \mathrm{C}\right)>[\mathrm{I}]^{-}\left(303{ }^{\circ} \mathrm{C}\right)>[\mathrm{Cl}]^{-}$ $\left(285^{\circ} \mathrm{C}\right)>\left[\mathrm{N}(\mathrm{CN})_{2}\right]^{-}\left(275^{\circ} \mathrm{C}\right)>[\mathrm{SCN}]^{-}\left(226^{\circ} \mathrm{C}\right)$ [29-32]. The purity of ILs is a very important issue and the influence of major contaminants such as water and chlorine ion on some of their physical properties has been discussed by Seddon et al. [33]. It is noteworthy that ILs are often determined as green solvents, but such character is disputable. Typical ILs consisting of halogen-containing anions may cause serious concerns if the hydrolytic stability of the anion is poor e.g. for $\left[\mathrm{AlCl}_{4}\right]^{-}$and $\left[\mathrm{PF}_{6}\right]^{-}$or if a thermal treatment of ILs used is required [29]. In both cases, additional effort is needed to avoid the 


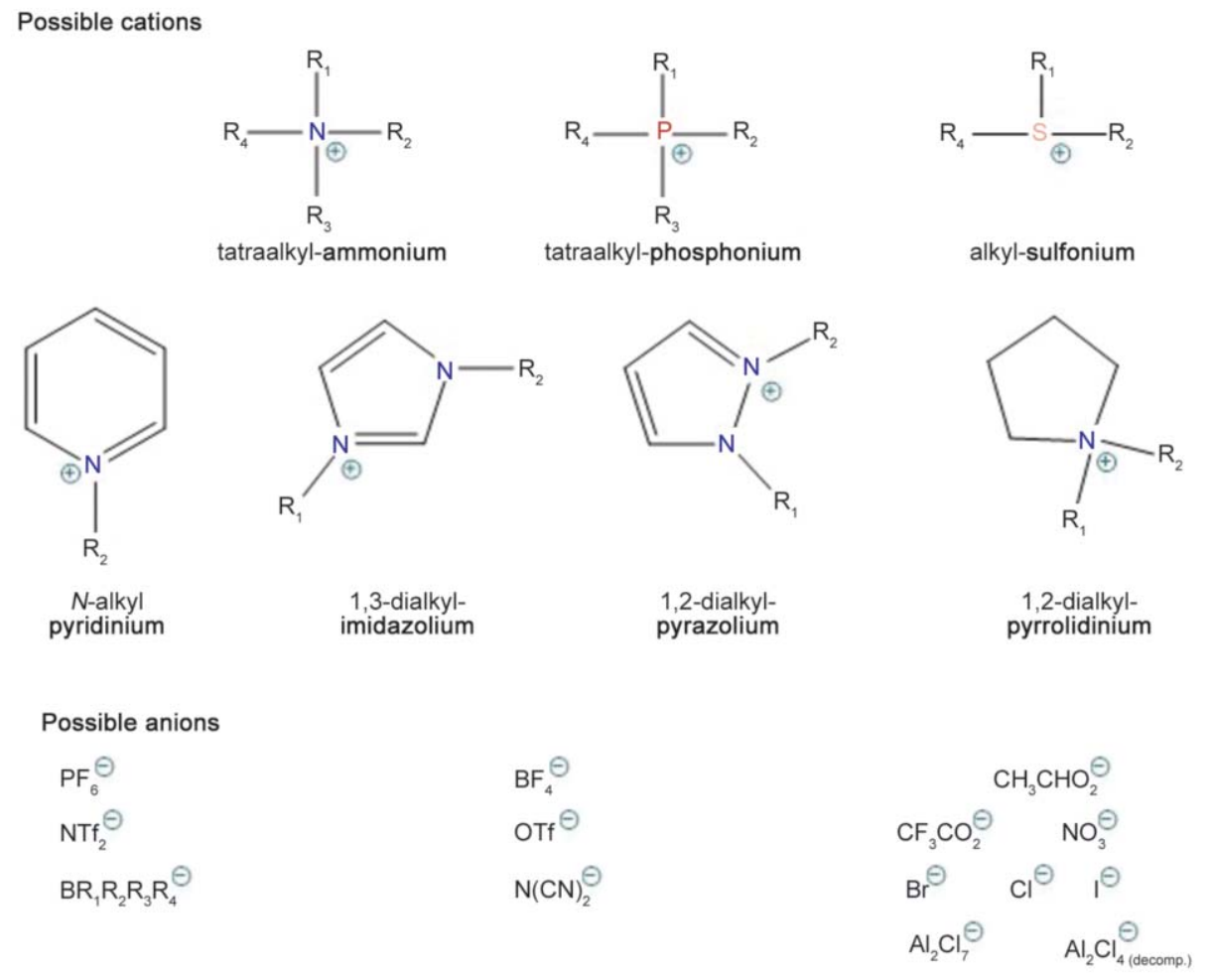

Figure 3. Structures of commonly used cations and anions species for ILs.

liberation of toxic and corrosive $\mathrm{HF}$ or $\mathrm{HCl}$ into the environment.

ILs can be divided into two broad categories, namely protic ILs (PILs) and aprotic ILs (AILs) [34-37]. PILs are formed in general by the transfer of a proton between an equimolar amount of Brønsted acid and base. Due to the «free» available proton, they are capable of hydrogen bonding, including proton acceptance and proton donation. AILs contain no acidic protons and exhibit characteristics significantly different from those of PILs (Table 1). It should be noted that AILs are more thermally and electrochemically stable than the corresponding PILs [38].

Due to their ability to be reused/recycled, most ILs could replace toxic industrial volatile organic compounds (VOCs) [39], and solve the following problems: (i) loss of solvent by uncontrolled evaporation, and (ii) traces of solvent in final product. In addition to the interactions existing in VOCs (hydrogen bonding, dipole-dipole and van der Waals interactions), ILs have ionic interactions (mutual electrostatic attractions or repulsion of charged particles), which

Table 1. Basic types of aprotic and protic ILs.

Protic ILs
- simpler and cheaper
to synthesize (no by-products)
- hogh fluidity and conductivity
- low melting points
- suitable for fuel cells


Table 2. Comparison of ionic liquids with organic solvents [20].

\begin{tabular}{|l|l|l|}
\hline \multicolumn{1}{|c|}{ Property } & \multicolumn{1}{c|}{ Organic Solvents } & \multicolumn{1}{c|}{ Ionic Liquids } \\
\hline Number of solvents & $>1000$ & $>1000000$ \\
\hline Applicability & Single function & Multifunction \\
\hline Catalytic ability & Rare & Common and tunable \\
\hline Chirality & Rare & Common and tunabl \\
\hline Vapour pressure & Obeys the Clausius-Clapeyron Equation & Negligible under normal conditions \\
\hline Flammability & Usually flammable & Usually nonflammable \\
\hline Solvation & Weakly solvating & Strongly solvating \\
\hline Tunability & Limited range of solvents available & Unlimited range means «designer solvents» \\
\hline Polarity & Conventional polarity concepts apply & Polarity concept questionable \\
\hline Cost & Normally inexpensive & 2 to 100 times the cost of organic solvents \\
\hline Recyclability & Green imperative & Economic imperative \\
\hline Viscosity $[\mathrm{cP}]$ & $0.2-100$ & $22-40000$ \\
\hline Density $\left[\mathrm{g} \cdot \mathrm{cm}{ }^{-3}\right]$ & $0.6-1.7$ & $0.8-3.3$ \\
\hline Refractive index & $1.3-1.6$ & $1.5-2.2$ \\
\hline
\end{tabular}

make them very miscible with polar substances. Generally speaking, ILs have properties that are quite different from those of organic solvents (cf. Table 2).

\section{Applications of ILs in thermosetting polymers}

Numerous advanced technologies require polymers possessing high thermal stability, inertness, excellent resistance towards solvents and aggressive media, etc. It is well known that highly crosslinked structures via covalent bonds are directly responsible for the high mechanical strength and high thermal stability, but at the same time provides a poor elasticity or elongation compared with thermoplastics or elastomers (Figure 4). Unlike thermoplastics, thermosets retain their strength and shape even when heated. In this context, the generation of high-performance thermosetting polymers in the presence of ILs may thus constitute an interesting challenge.

In the next sections the application of ILs in epoxy based thermosets as catalysts, curing agents, electro- conductive components, plasticizers, lubricants and porogens is presented (Figure 5). Additionally, using ILs in high-performance Cyanate Ester Resins (CERs) will be discussed as well.

\subsection{Epoxy resins}

\subsubsection{Ionic liquids as catalytic agents}

ILs represent an exciting new class of catalytic or/and crosslinking agents for thermosetting polymers, especially for epoxy resins [40-50]. The first trial of using 1-butyl-3-methylimidazolium tetrafluoroborate $[\mathrm{BMIm}]\left[\mathrm{BF}_{4}\right]$ IL for cross-linking of epoxy resin was described by Kowalczyk and Spychaj in 2003 [41]. Palmese's team for the first time [47] used 1-ethyl-3-methylimidazolium dicyanamide [EMIm] $\left[\mathrm{N}(\mathrm{CN})_{2}\right]$ in a range of $3-20 \mathrm{wt} \%$ and found a lower cross-linking temperature than that reported

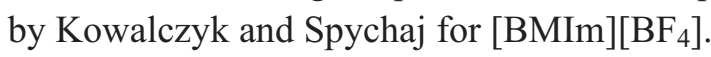

As discussed in the literature [40, 41], imidazoliumbased ILs act as curing agents for the epoxy systems at high temperature. Liebner et al. [51] suggested

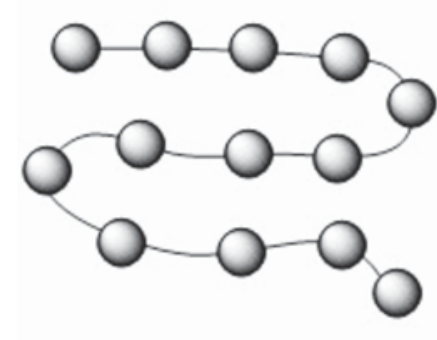

Thermoplastic

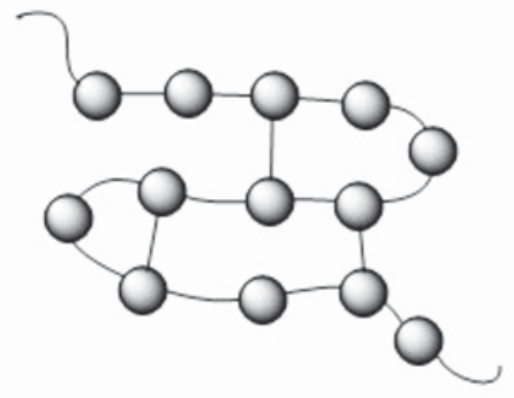

Elastomer

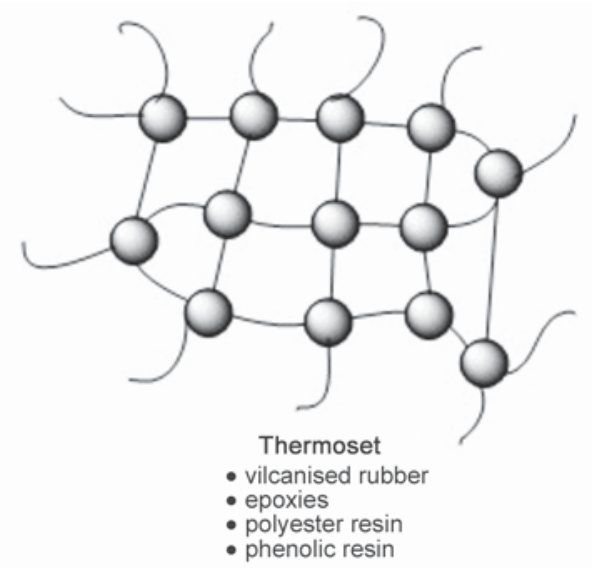

Figure 4. Schematical image of the structure of thermoplastics, elastomers and thermosets. 


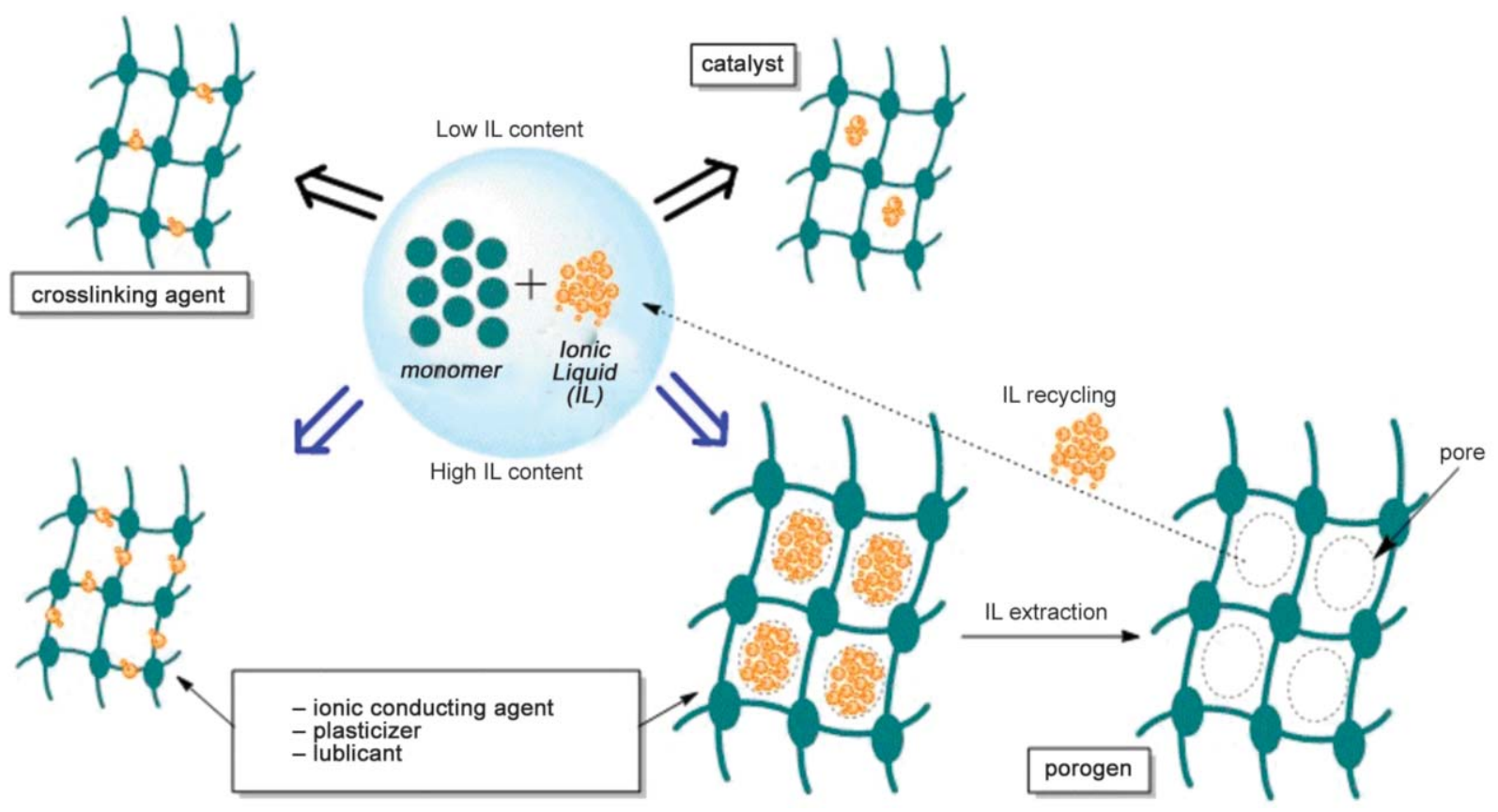

Figure 5. Potential applications of ionic liquids in thermosetting resins.

that such ILs may undergo a thermal decomposition leading to formation of imidazole and other decomposition products. In an early study, Farkas and Strohm, reported about the high catalytic activity of imidazoles for curing of epoxy resins, proving that the imidazole became permanently attached to the polymer chain [52]. The curing kinetics and mechanisms of diglycidyl ether of bisphenol A (DGEBA) using imidazole and 1-methyl imidazole as curing agents were studied by Ghaemy and Sadjady [53]. Soares et al. [42] synthesized epoxy crosslinked materials containing $N, N^{\prime}$-dioctadecylimidazolium iodide (1-12 wt \%) by curing a mixture of DGEBA with 4,4'-methylene-bis 3-chloro-2,6-diethylaniline (MCDEA) as a hardener. It was found that the high temperature used for curing might favour some degradation of the IL, generating new species, which also took part in the curing process.

Mąka et al. [46] also reported that reaction activity of ILs towards epoxy resins was connected with its thermal decomposition characteristics. They prepared and investigated the epoxy compositions with ILs possessing the imidazolium cation with alkyl chains of different length (butyl or decyl), and different anion type $\left(\left[\mathrm{N}(\mathrm{CN})_{2}\right]^{-},[\mathrm{BF} 4]^{-},[\mathrm{Cl}]^{-}\right)$, the ILs concentration was varied as well $(1,3$, or $8 \mathrm{wt} \%)$. On the basis of the results, the authors concluded that i) the curing process started at lower temperature $(120 \rightarrow$ $150^{\circ} \mathrm{C}$ ) when ILs with $[\mathrm{N}(\mathrm{CN}) 2]^{-}$anion were applied, in comparison with those containing $\left[\mathrm{BF}_{4}\right]^{-}$ anions $\left(200 \rightarrow 240^{\circ} \mathrm{C}\right)$; ii) the alkyl chain length of imidazolium cation influenced slightly the onset temperature curing range: for decyl substituent, $200 \rightarrow 240^{\circ} \mathrm{C}$, and butyl, $210 \rightarrow 230^{\circ} \mathrm{C}$; iii) as a rule bimodal exotherms appeared on DSC thermograms, the first was placed at a lower temperature range above $110^{\circ} \mathrm{C}$ (compositions with ILs and basic $\left[\mathrm{N}(\mathrm{CN})_{2}\right]^{-}$anion) and the second was placed above $250^{\circ} \mathrm{C}$ (compositions with ILs bearing $[\mathrm{BF} 4]^{-}$ anion). The observed bimodal exotherms and FTIR absorption bands at $1740-1750 \mathrm{~cm}^{-1}$ were explained by the proposed mechanism of epoxy resin anionic polymerization initiated by thermal decomposition products of 1,3-dialkylimidazolium liquids. In 2015, the same group [49] performed comparison of two dicyanamide ILs with various cation types: imidazolium, i.e. 1-ethyl-3-methylimidazolium dicyanamide $\left([\mathrm{EMIm}]\left[\mathrm{N}(\mathrm{CN})_{2}\right]\right)$ and phosphonium, i.e. (trihexyltetradecyl phosphonium dicyanamide ([THTDP] $\left.\left[\mathrm{N}(\mathrm{CN})_{2}\right]\right)$. The composition of neat epoxy resin with IL exhibited prolonged storage times, namely $>45$ days and $>70$ days, when $[$ EMIm] $]\left[\mathrm{N}(\mathrm{CN})_{2}\right]$ and $[\mathrm{THTDP}]\left[\mathrm{N}(\mathrm{CN})_{2}\right]$ was applied, respectively. Increasing the IL amount in epoxy composition resulted in shortening the pot life, and this influence was more pronounced in the case of $[\mathrm{EMIm}]\left[\mathrm{N}(\mathrm{CN})_{2}\right]$. It was also shown that DSC thermograms for compositions with [EMIm] $\left[\mathrm{N}(\mathrm{CN})_{2}\right]$ were bimodal with the first maximum $\left(T_{\max }\right)$ in a temperature range from 136 to $133^{\circ} \mathrm{C}$ and the second one from 180 to $164^{\circ} \mathrm{C}$. Epoxy compositions with $[$ THTDP $]\left[\mathrm{N}(\mathrm{CN})_{2}\right]$ exhibited unimodal thermograms 
with $T_{\max }$ from 180 to $170^{\circ} \mathrm{C}$. A simple relationship between IL thermal stability and its activity as epoxy resin curing agent was found: the observed $T_{\max }$ values for the second exothermal peaks of investigated epoxy curing process correlated qualitatively with the thermal degradation of IL. It should be noted that epoxy compositions cured with $6 \mathrm{wt} \%$ $\left[\right.$ THTDP] $\left[\mathrm{N}(\mathrm{CN})_{2}\right]$ showed higher transparency $(\approx 85 \%)$ in comparison to that with $3 \mathrm{wt} \%$ [EMIm] $\left[\mathrm{N}(\mathrm{CN})_{2}\right]$ (black opaque) [49].

Soares et al. [43] has performed a comparative study on the effects exerted by different ILs (imidazolium, pyridinium and phosphonium) with long alkyl chains on DGEBA curing at high temperature. The hardener used for the curing process was MCDEA. The results clearly demonstrated once again that imidazolium- and pyridinium-based ILs may decompose at high temperature used for the curing process, and the resulting decomposition products (imidazole or pyridine [54-56], respectively) could act as additional curing agents for epoxy systems. In contrast, phosphonium-based IL did not participate in the curing process and/or displayed the highest thermal stability or if they decomposed, the products formed did not react with the epoxy prepolymer. However, there has been some discrepancy concerning the catalytic activity of phosphonium-based IL on epoxy resins curing. Nguyen et al. [57] substantiate the use of different amounts $(9,17,23 \mathrm{wt} \%)$ of tributyl (ethyl) phosphonium diethyl phosphate (CYPHOS ${ }^{\circledR}$ IL169) and trihexyl (tetradecyl) phosphonium bis 2,4,4-(trimethyl pentyl)-phosphinate (CYPHOS ${ }^{\circledR}$ IL104) for DGEBA curing. In both cases, all the samples were homogeneous except the mixtures containing 17 and $23 \mathrm{wt} \%$ IL104, in which some exudation was observed. The results clearly showed that $9 \mathrm{wt} \%$ IL104 was an excellent alternative to a large amount of amines (40 wt\% Jeffamine D400) required for crosslinking of epoxy resins. The lower reactivity of phosphate anion was explained by its lower basicity compared to phosphinate anion (higher $\mathrm{pKa}$ ): phosphinate anion possessing two alkyl groups exerts an inductive donor effect, which leads to enrichment of electrons for the $-\mathrm{OH}$ bond and makes very difficult the rupture of the $-\mathrm{OH}$ bond. Soares et al. [58] highlighted the double role of CYPHOS ${ }^{\circledR}$ IL104 as a curing agent for the epoxy prepolymer and an excellent dispersant aid for the multiwalled carbon nanotubes (MWCNTs), giving rise to materials which combine excellent electrical conductivity and high thermal properties. Mąka et al. [50] reported that phosphonium ionic liquid [trihexyltetradecylphosphonium bis(2,4,4-trimethylpentyl) phosphinate played a triple function: carbon nanofiller dispersing medium, catalytic curing agent, and antiflamming additive. With increasing IL content $(3 \rightarrow 8 \mathrm{wt} \%)$ in epoxy resin, the curing reaction started at lower temperature as determined by rheometry $\left(145 \rightarrow 125^{\circ} \mathrm{C}\right)$ and DSC $\left(133 \rightarrow 118^{\circ} \mathrm{C}\right)$. Only slight influence of carbon nanotubes or graphene $(0.25-1.0 \mathrm{wt} \%)$ on curing characteristics of epoxy systems was observed.

Nguyen et al. [59] reported a new way to synthesize epoxy networks using 9-23 wt\% of phosphoniumbased ILs combined with phosphinate, carboxylate, and phosphate counter-anions. In all the cases, ILs displayed a high reactivity towards epoxy prepolymer and led to the formation of epoxy networks with high epoxy group conversion (up to $90 \%$ ). The authors have demonstrated that the reactivity of ILs is controlled by their basicity and is ranked in the following order: carboxylate $>$ phosphinate $>$ phosphate [59]. The findings of this study indicated that ILs were excellent alternatives to conventional amines as lower amounts of the former are required for crosslinking reaction: $9 \mathrm{wt} \%$ for phosphinate and carboxylate, $23 \mathrm{wt} \%$ for phosphate compared to $25 \mathrm{wt} \%$ for Jeffamine D230 and $35 \mathrm{wt} \%$ for MCDEA.

So far imidazolium-based ILs have been more often applied in epoxy resin systems as curing agents than phosphonium ones [50]. However, the reasons why one might be interested in phosphonium ILs, even in industrial processes, include their availability and cost.

\subsubsection{Ionic liquids as ionic conducting agents}

ILs are promising candidates for novel high-performance electrolytes for electrochemical devices such as lithium-ion batteries and electronic double layer capacitors. ILs have low viscosity and excellent ionic conductivity up to their decomposition temperature. Nevertheless, a drawback for practical application is that IL fluidity may cause liquid electrolyte leakage. Ohno and co-workers attempted to polymerize ILs composed of imidazolium substituted methacrylates [60-62]. However, polymerization of ionic compounds often reduces the molecular motion and provides low ionic conductivity. To solve this problem, polymers which have three-dimensionally highly crosslinked structures and possess excellent physicochemical properties could be used. 
DGEBA/Jeffamine D400 system was modified with 2.5 and $5.0 \mathrm{wt} \%$ of ILs based on imidazolium and phosphonium cations with long alkyl chains, such as $N, N$ '-dioctadecyl-imidazolium iodide, or octadecyltriphenylphosphonium iodide ([ODTPP][I]) [63]. These results clearly demonstrated the higher conductivity of DGEBA/D400/[ODTPP][I] system compared to the others although the conductivity values were not high enough for a solid electrolyte, probably because of the low amount of IL used.

Polymer networks confining an 1-ethyl-3-methylimidazolium bis(trifluoromethane sulfonyl) imide ([EMIm][TFSI]), were prepared [64] by curing a mixture of DGEBA and tetrafunctional epoxy resins with tetraethylenepentamine (TEPA) in the presence of ionic liquid. The ionic liquid confinement, ionic conductivity, mechanical strength, and morphology of the materials strongly depended on the ionic liquid content. At a low [EMIm][TFSI] content ( $<40 \mathrm{wt} \%$ ), the material tightly confined the ionic liquid and showed little ionic conductivity with a high Young's modulus. This seems reasonable because there are no freely mobile ions in the samples, in which rigid and glassy polymer network locally confine ions. At a high IL content ( $>40 \mathrm{wt} \%$ ), the material did not tightly confine the IL showing higher ionic conductivity. The microphase separation between the [EMIm][TFSI] and the epoxy networked polymer was observed by scanning electron microscopy (SEM). The ionic conductivity of the DGEBA/ TetradX/TEPA/(50 wt\%) [EMIm][TFSI] was equal to $1.0-12.0 \cdot 10^{-2} \mathrm{~S} / \mathrm{m}$ in the frequency range from 1 to $100 \mathrm{KHz}$, which is quite high and corresponds to about $1 / 8$ of the reported bulk [EMIm] [TFSI] conductivity $\left(84.0 \cdot 10^{-2} \mathrm{~S} / \mathrm{m}\right)$. Subsequently, Matsumoto et al. [65] synthesized the highly flexible ion conductive films of an epoxybased crosslinked polymer containing an ionic liquid having a quaternary ammonium salt structure. The polymers having trimethylammonium bis(trifluoromethanesulfonyl)imide groups were synthesized by heating a mixture of diepoxide, glycidyl trimethylammonium bis(trifluoromethanesulfonyl)imide (GTMATFSI), and diamine curing reagent. Ethylene glycol diglycidyl ether (EGGE), poly(ethylene glycol) diglycidyl ether (PEGGE), and poly(propylene glycol) diglycidyl ether (PPOGE) were used as diepoxides, and ethylene glycol bis(3-aminopropyl) ether (EGBA), poly(ethylene glycol) diglycidyl ether bis(3-aminopropyl ether) (PEGBA), and polypropylene glycol bis(2-aminopropyl ether) (PPOBA) were used as diamine curing reagents. The obtained networks having quaternary ammonium structure showed high thermal stability (temperature of $5 \mathrm{wt} \%$ decomposition above $270^{\circ} \mathrm{C}$ ), low crystallinity, low glass transition temperature, and good ionic conductivity. In particular, the crosslinked polymers consisting of poly(ethylene glycol) segments showed high ionic conductivity $\left(>0.1 \cdot 10^{-2} \mathrm{~S} / \mathrm{m}\right)$ at room temperature and reached $5.8 \cdot 10^{-2} \mathrm{~S} / \mathrm{m}$ for EGGE-GTMATFSI-1.2/PEGBA and $4.1 \cdot 10^{-2} \mathrm{~S} / \mathrm{m}$ for PEGGE/ GTMATFSI-1.2/ PEGBA at $90^{\circ} \mathrm{C}$, which is also quite high for a solid polymeric material. These networks were mechanically strong and tough enough to produce self-standing thin films and will be useful materials for application as ionic conductive membranes in electrochemical devices.

Livi et al. [66] designed IL-containing polymer networks, which could be employed as new polymer electrolytes. They used trihexyl(tetradecyl)phosphonium IL with dicyanamide counteranion as functional additives to synthesize nanostructured epoxy networks with very high mechanical properties and thermal stability $\left(>400^{\circ} \mathrm{C}\right)$. In addition, TEM micrographs (Figure 6) showed the formation of ionic clusters of the size of 20-30 nm with excellent distribution (characterized by the white spots) for the epoxy

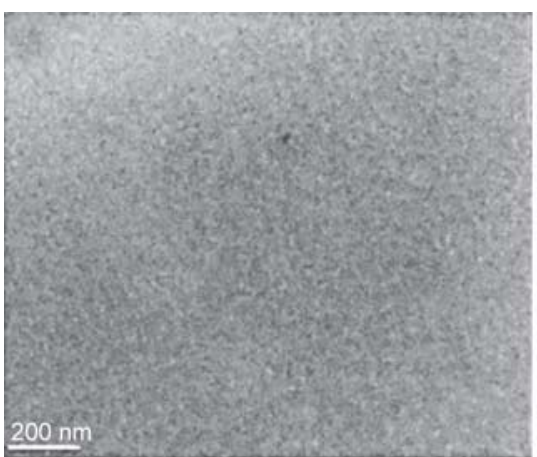

a)

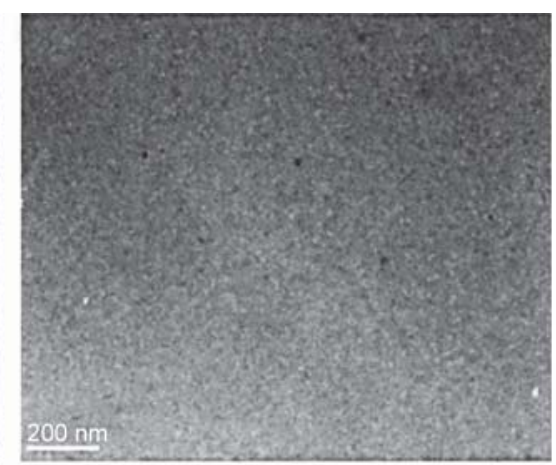

b)

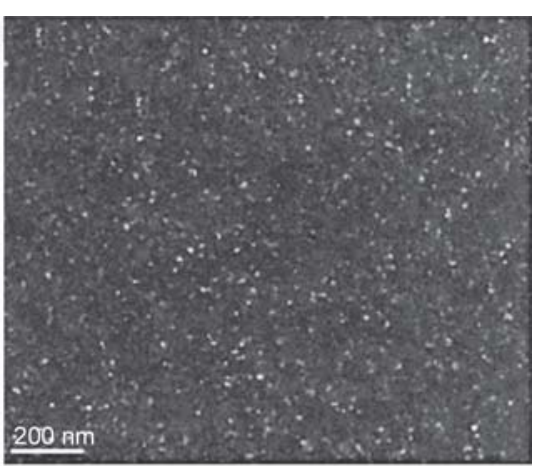

c)

Figure 6. TEM micrographs of epoxy networks cured with phosphonium dicyanamide IL [wt\%]: (a) 5, (b) 9, (c) 23 [66]. 
network loaded with the highest concentration (23 wt $\%$ ) of this IL. These results are promising and open new perspectives in the field of energy where the IL can be used as ionic channels for lithium salts to ensure suitable conduction properties [66].

Shirshova et al. [67] prepared a series of epoxy resinionic liquid composites to identify the optimum system microstructure required to achieve a high level of multifunctionality. Structural electrolytes based on fully formulated commercially available epoxy resins (pure one with trademark $\mathrm{MVR}^{\circledR} 444$ and toughened ones, $\mathrm{MTM}^{\circledR} 57$ and $\mathrm{VTM}^{\circledR} 266$ ) were obtained by adding the mixture of bis(trifluoromethane) sulfonimide lithium salt (LiTFSI) and ethyl-3-methylimidazolium bis(trifluoromethylsulfonyl)imide ([EMIM][TFSI]) ionic liquid. Detailed temperaturedependent ionic conductivity measurements were carried out using dielectric spectroscopy in a temperature range of -30 to $60^{\circ} \mathrm{C}$. The ionic conductivity was extracted from the plateau region of each dielectric spectrum (Figure 7). At only $30 \mathrm{wt} \%$ of structural resin $\left(\mathrm{MVR}^{\circledR} 444\right)$ and $70 \mathrm{wt} \%$ of IL-based mixture, containing $17 \mathrm{wt} \%$ of the Li salt, stiff monolithic plaques with thicknesses of $2-3 \mathrm{~mm}$ possessing room temperature ionic conductivity of $8.0 \cdot 10^{-2} \mathrm{~S} / \mathrm{m}\left(0.5 \cdot 10^{-2} \mathrm{~S} / \mathrm{m}\right.$ at $\left.-20^{\circ} \mathrm{C}\right)$ and Young's modulus of $0.2 \mathrm{GPa}$ were obtained. The authors concluded that the room temperature conductivity close to $8.0 \cdot 10^{-2} \mathrm{~S} / \mathrm{m}$ was not only a desirable value for supercapacitor applications, but was also high enough to potentially consider thin films of MVR ${ }^{\circledR} 444 / 30$ as separation membranes for Li-ion batteries [67].

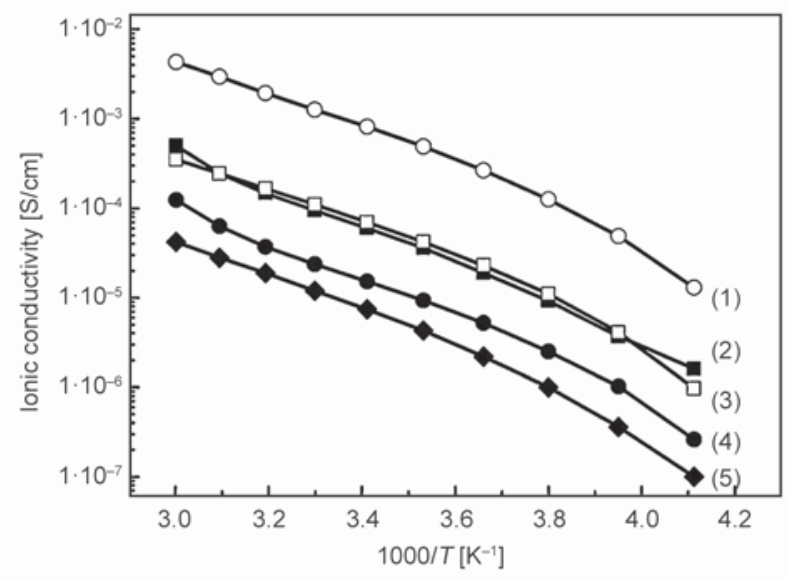

Figure 7. Temperature dependence of ionic conductivity of samples with varying resin contents [wt\%]: (1) 30; (2) 50 ; (3) 40; (4) 50; (5) 50 .

Samples (1), (3), (4) - based on $\mathrm{MVR}^{\circledR} 444$; (2) - $\operatorname{VTM}^{\circledR} 57 ;(4)-\mathrm{VTM}^{\circledR} \cdot 266[67]$.
Soares et al. [68] investigated the influence of different ILs based on tetraalkylphosphonium cations containing different counter-anions, such as dicyanamide, bis(trifluoro-methanesulfonyl)imide and dodecylbenzene sulfonate on the ionic conductivity of epoxy resin based on DGEBA cured with poly(propylene glycol) bis(2-aminopropyl ether). A significant increase in the ionic conductivity $\left(0.01 \cdot 10^{-2} \mathrm{~S} / \mathrm{m}\right.$ at $110^{\circ} \mathrm{C}$ ) was observed with the presence of $13 \mathrm{wt} \%$ of CYPHOS 105, mainly at a temperature higher than $T_{\mathrm{g}}$, when the ion mobility increased. Other epoxyIL systems reported in the literature possess higher conductivity values, but with the higher IL content $(60-80 \mathrm{wt} \%)$ [67]. The incorporation of a 1-decyl-3methylimidazolium bromide ([DMIm] [Br] ) content as high as $50 \mathrm{wt} \%$ within the epoxy matrix resulted in solid and flexible electrolyte with high thermal stability and ionic conductivity of around $0.1 \cdot 10^{-2} \mathrm{~S} / \mathrm{m}$ at room temperature, which increased up to $10 \cdot 10^{-2} \mathrm{~S} / \mathrm{m}$ at $170^{\circ} \mathrm{C}$ [69]. It was concluded that this electrolyte presented a prodigious potential for applications at high temperature in electrochemical devices like batteries and supercapacitors, and the flexibility of this solid electrolyte persisted at low temperature because of its low glass transition temperature. Furthermore, leakage problems were not observed.

\subsubsection{Ionic liquids as plasticizers}

A plasticizer is a substance incorporated into a polymer to increase its flexibility, workability or distensibility. Normally, plasticizers have a large influence on physical, chemical, and electrochemical properties of modified polymers: for instance, they reduce melt viscosity, temperature of a second order glass transition $\left(T_{\mathrm{g}}\right)$ or elastic modulus of a polymer. The plasticizers used in the industry are mostly derivatives of phthalates, which represent approximately 70 percent of the market. However, due to their toxicity, academic and industrial researchers have been looking for new plasticizers. In fact, RTILs have the necessary qualities of a good plasticizer: i) excellent melting properties, ii) minimal interaction with resins at room temperature and iii) non-volatility at ambient conditions. As one can conclude, RTILs can be utilized as efficient plasticizers to manage mechanical properties of thermosetting polymers, at that the chemical nature of organic cations and anions plays a significant role in the distribution of ionic domains in the polymer matrix. According to the literature, 
imidazolium and pyridinium ILs lead to the formation of aggregates of ionic clusters, while phosphonium ILs generate a structuration at a nanoscale denoted as «spider-web» morphology [52]. Thus, it is possible to control the plasticization effect of thermosets by varying IL molar mass and chemical structure.

Lu et al. [3] reported a significant decrease in the $T_{\mathrm{g}}$, of epoxy networks by using several types of ILs, and this effect was more pronounced in the systems modified with imidazolium-based ILs, than that in the systems containing phosphonium-based ILs. DuchetRumeau and Gérard's group successfully used $N, N^{\prime}$ dioctadecylimidazolium iodide with long alkyl chains as a new additive for epoxy networks [42]. The $T_{\mathrm{g}}$ value as determined at the maximum of the tan $\delta$ peak decreased as the amount of the IL increased. This behaviour suggested a plasticizing effect of the IL imparted by the presence of the two long alkyl chains in its structure. The authors noted that the storage moduli at temperatures below $T_{\mathrm{g}}$ were higher in the thermosets containing IL probably because of the good interactions between the components (Figure 8) [42]. At temperatures above $T_{\mathrm{g}}$, the modulus of the system containing $1 \mathrm{wt} \%$ of IL was higher than that of the pure epoxy network, indicating high interactions between the blend components. However, when increasing the amount of IL, the moduli in this region decreased, suggesting that the plasticizing effect imparted by the long alkyl groups in the IL molecules contributed more for this property than the interactions between the components. The $T_{\mathrm{g}}$ tendency found in DSC experiments was similar to that detected by DMA analysis and also confirmed the plasticizing effect of the IL.

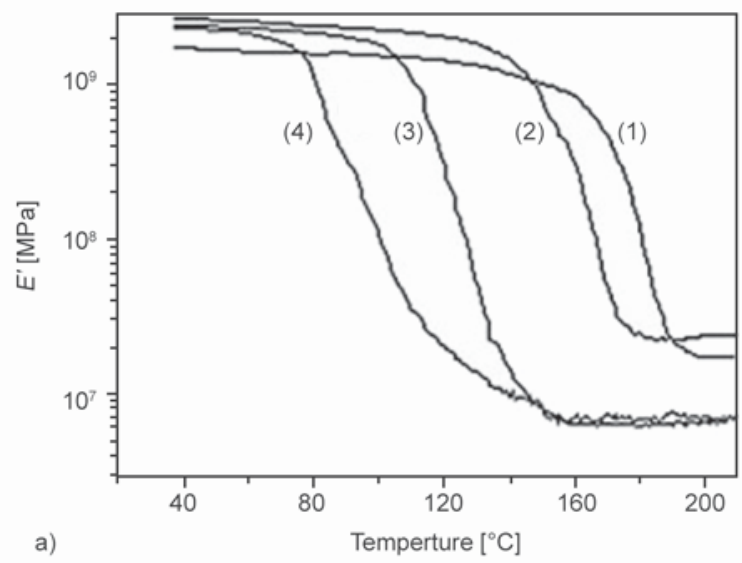

Sanes and coworkers [70-76] also reported that addition of IL to epoxy resins enhanced chain mobility and provided a plasticizing effect as well as reduced friction coefficient and wear rate of the final materials.

\subsubsection{Ionic liquids as lubricants}

It is known that the poor tribological performance of epoxy resins is a major limitation in many applications. The main strategy which has been followed in order to improve their resistance consists in using internal lubricants. The first IL used as an inner lubricant of epoxy resin was the short alkyl chain 1ethyl-3-methylimidazolium tetrafluoroborate ([EMIm] $\left.\left[\mathrm{BF}_{4}\right]\right)$ added in a concentration range between 0.5 and $3.3 \mathrm{wt} \%$ [70]. It was found that dry friction coefficients decreased exponentially from 0.73 to 0.29 as the IL proportion increased and wear resistance was improved in several orders of magnitude for a critical IL concentration of $2.7 \mathrm{wt} \%$.

Hameed et al. [77] described the controlled mechanical behaviour of epoxy resin from brittle to ductile and even to elastomeric behaviour, when high amounts (10-60 wt\%) of the 1-butyl-3-methylimidazolium chloride IL were added. The authors proposed the formation of electron donor-electron acceptor complexes between the hydroxyl groups of the epoxy chains and bulky IL ions, resulting in high modulus and toughness. At elevated temperatures, these complex bonds break and the presence of detached bulky ions leads to flexible networks and reduced glass transition region.

Saurín and coworkers $[71,72]$ claimed a good tribological performance and even self-healing effect of abrasion surface damage on an epoxy resin material with the addition of a relatively high (7-12 wt\%)

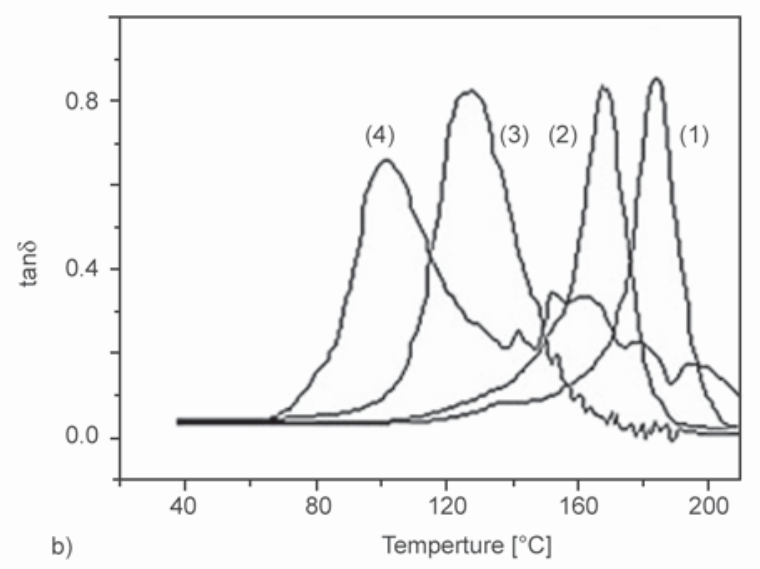

Figure 8. Temperature dependencies of storage modulus (a) and tan $\delta$ (b) of DGEBA/IL/MCDEA networks as a function of the IL content [wt\%]: (1) 0, (2) 1.0, (3) 1.6 , (4) 3.0 [42]. 
amount of the 1-octyl-3-methylimidazolium tetrafluoroborate $\left([\mathrm{OMIm}]\left[\mathrm{BF}_{4}\right]\right)$. It was the first paper describing a self-healing process induced by an IL additive [71]. From the results, it was concluded that the addition of IL (i) reduced hardness and tensile strength, (ii) increased elongation at break by a $42 \%$, (iii) showed an area reduction of approximately $55 \%$ after $5 \mathrm{~h}$, (iv) induced a self-healing process with a $41 \%$ recovery after $30 \mathrm{~min}$ and a total self-repair of the abrasion damage under multiple scratching after $22 \mathrm{~h}$ at room temperature, and (v) reduced the surface damage by $88 \%$ with respect to individual network, after $24 \mathrm{~h}$ at room temperature (single scratches under the maximum load of $20 \mathrm{~N}$ ). Further investigation [72] emphasized that material with $7 \mathrm{wt} \%$ IL content demonstrated a lower friction coefficient than the neat epoxy, due to its lower instantaneous surface damage. In contrast, the self-healing ability over time increased with increasing IL concentration with maximum obtained for the $9 \mathrm{wt} \%$ IL proportion $(96.2 \%$ reduction after $22 \mathrm{~h}$ at room temperature). The surface topography and cross-section profiles with time after the scratch tests on epoxy resin containing $12 \mathrm{wt} \%$ of $[\mathrm{OMIm}]\left[\mathrm{BF}_{4}\right]$ are shown in Figure 9 [72]. Authors concluded that interactions between the cation-anion pairs of the $[\mathrm{OMIm}]\left[\mathrm{BF}_{4}\right]$ and the polar groups of the polymer chains reduced the brittle behaviour of the resin and the permanent

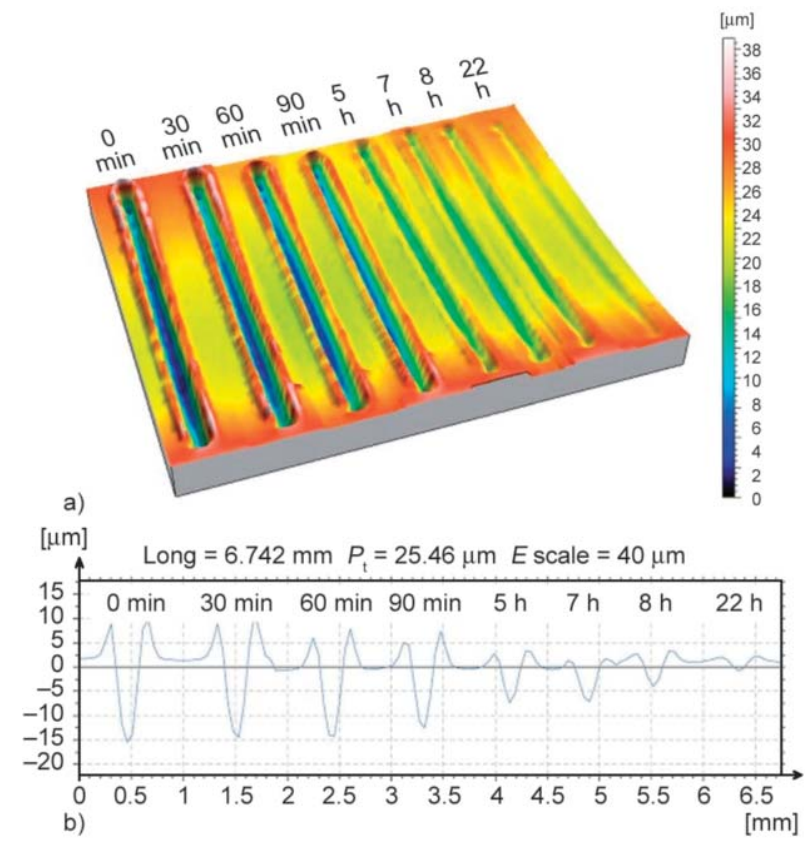

Figure 9. Surface topography (a) and cross section profiles (b) for the evolution of the wear track on a surface of epoxy resin/[OMIm] $\left[\mathrm{BF}_{4}\right](12 \mathrm{wt} \%)$ [72]. damage produced by crack propagation under load and could be responsible for the observed self-healing behaviour.

It was found that $[\mathrm{OMIm}]\left[\mathrm{BF}_{4}\right]$ showed an outstanding friction-reducing and anti-wear performance for the epoxy resin-stainless steel contact, which was further improved by addition of $\mathrm{ZnO}$ nanoparticles [73], graphene [74] or single walled carbon nanotubes (SWCNTs) [75]. The reinforcement effect of graphene responsible for the good tribological performance, while IL acts as a plasticizing agent, increasing chain mobility, reducing $T_{\mathrm{g}}$ and shifting the storage modulus onset, the loss modulus and $\tan \delta$ peaks to lower temperatures [74]. SWCNTs and the IL show a synergistic effect when are added to an epoxy resin matrix, being able to reduce both friction coefficient, in a $53 \%$, and wear rate, in a $86 \%$, with respect to neat epoxy resin under pin-on-disc sliding contact against stainless steel [75]. Very similar effects can be achieved with SWCNTs pre-modified by ILs.

Recently, Avilés et al. [76] synthesized and characterized a new self-lubricating, wear resistant epoxy polymer by addition of $9 \mathrm{wt} \%$ of the room-temperature protic ionic liquid - tri-[bis(2-hydroxyethyl)ammonium)] citrate (DCi). It was shown more than $50 \%$ reduction of the friction coefficient with respect to neat epoxy resin, and a polished surface, in contrast with the severe wear that takes place in the case of neat epoxy resin. The high polarity of the protic ionic liquid molecules produced low miscibility of the liquid phase within the epoxy matrix and reduces the wettability of the resin surface.

\subsubsection{Ionic liquids as porogens}

The novel peculiarity of ILs as «designer solvents» is the possibility to design porous thermosets with the necessary properties for the specific applications. The basic requirements to porogens are as follows: (i) boiling point higher than the temperature of polymer synthesis; (ii) inertness towards basic components of polymer synthesis; (iii) predetermined ratio of polarity and solubility parameters of monomer, polymer, and porogen. The solubility parameter $(\delta$, $\left.\left(\mathrm{J} / \mathrm{cm}^{3}\right)^{1 / 2}\right)$ of the polymer is defined as the square root of the cohesive energy density in the amorphous state at room temperature [78], which provides a numerical estimation of the degree of interaction between materials (see Equation (1)): 


$$
\delta=\left(\frac{E_{\mathrm{coh}}}{V}\right)^{1 / 2}
$$

The solubility parameter is crucial for a porogen selection, and it is used to compare the solvation, miscibility, and swelling properties of the components used. The consideration of nature and possible interactions of porogen-polymer, porogen-monomer $(s)$, and porogen-initiator is also an important issue during synthesis of porous materials. Mohamed et al. [79] reported that the closer the solubility parameters of a porogen, reactants (monomer/crosslinker/polymer), the greater the surface area and the smaller the pore volume, while the smaller surface area and the higher pore volume in porous polymers could be reached at higher difference in solubility parameters of the components used. The uni-modal (micro, meso, or macroporous) polymer can be obtained by varying the type and amount of a porogen. In addition to this, bi-modal (micro-meso, meso-macro, or micro-macro) porosity can be generated using a porogen mixture or varying the porogen ratio. A low molar mass porogen is generally preferred to obtain the smaller pore size, which results into a greater surface area and vice-versa for a high molar mass porogen [80]. However, increasing the molar mass of a porogen increases the viscosity of the polymerization reaction composition, and it is recommended to use high molar mass porogens in combination with a porogen of low molar mass [81]. Therefore, the use of RTILs as porogens for the preparation of porous polymers [82-86] has some distinct advantages: (i) ILs are thermally stable

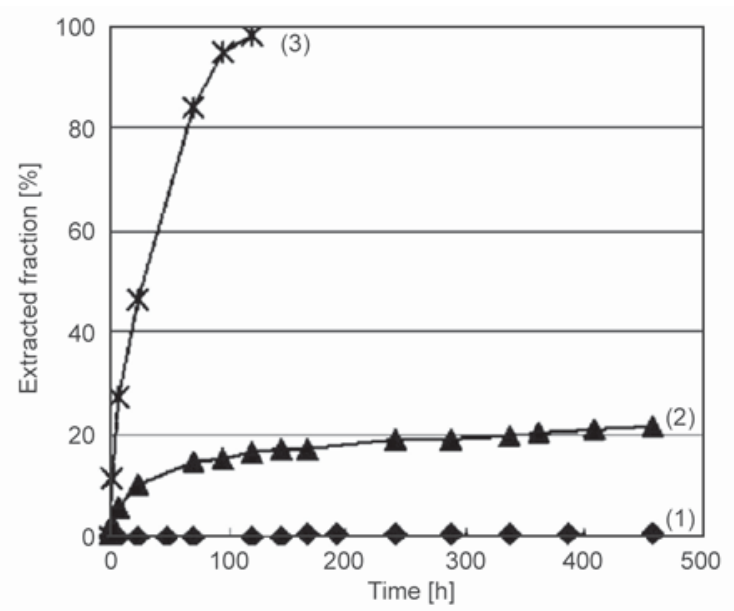

Figure 10. Time dependence of the extracted ionic liquid fraction from films of DGEBA/Tetrad-X/TEPA with [EMIm][TFSI] (1), [HMIm][TFSI] (2) and [BMIm][TFSI] (3) (extraction solvent: acetone) [64]. and nonvolatile and can be easily recycled; (ii) the morphology and porous structure can be easily changed through a proper selection of the structural features of the IL used; (iii) pore diameter can be managed by varying the amount of IL used; (iv) due to extremely low viscosity, ILs can be used as porogens without using any additional solvent.

Nowadays, several researchers have studied the extraction of ILs from epoxy polymer networks, however no-one has reported on the characterization of porous thermosets obtained thereof. Matsumoto and Endo [64] extracted the IL from polymer/IL composites in order to examine the morphologies of the cross-linked materials. Figure 10 shows the results of acetone extraction of various ILs from DGEBA/ TEPA/IL epoxy network systems. The IL confinement was in the order [EMIm][TFSI] > $[$ HMIm] $[$ TFSI $]>[$ BMIm] $[$ TFSI $]$, which was the opposite order of the steric hindrance of the cations. The reason for this remained unknown, but the authors assumed that the hexyl or benzyl groups in the cationic part may increase the compatibility of the IL with the epoxy network that provides the enhanced segmental motion of the network, so the IL can easily escape from the network. Materials confining IL were insulating with a high Young's modulus, while those not confining IL were ion conducting with a low Young's modulus. SEM observation revealed that the drastic change of the fundamental properties of the epoxy materials could be due to the morphology transition of the materials, in which the IL transformed discrete phases to continuous phases in the epoxybased networks. These results suggest that the addition of IL can be a new and facile method to control the morphology of polymer networks.

Shirshova et al. [67] reported that there were no dimensional changes observed as a result of electrolyte ([EMIM][TFSI] + LiTFSI) extraction removing more than $>95 \mathrm{wt} \%$ of the original IL-based electrolyte content from an epoxy network (MVR $\left.{ }^{\circledR} 444\right)$. The SEM images of all the samples showed a bicontinuous morphology (Figure 11). It seemed likely that MVR $^{\circledR} 444$ formed a fully miscible one-phase system at the cure temperature, but that phase separation occurred at an earlier stage during the polymerization as a result of its lower miscibility with the ionic liquid. The authors concluded that this system based on commercial components could be readily applied to the development of structural electrical energy storage composite devices. 


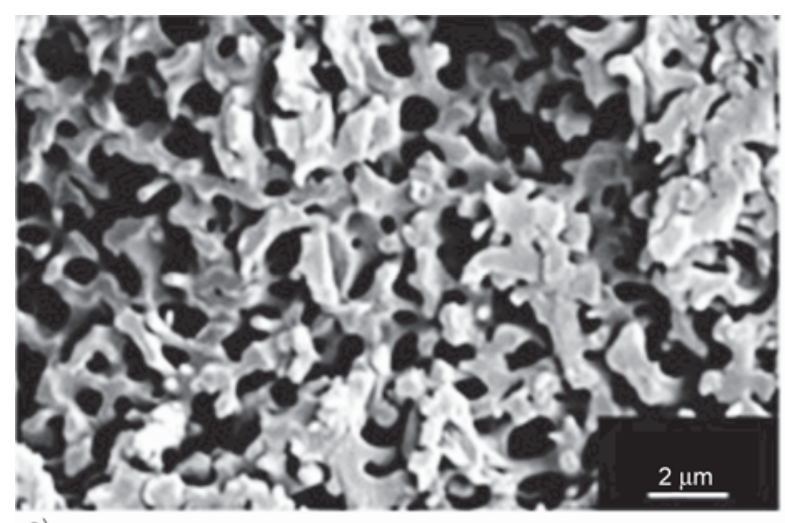

a)

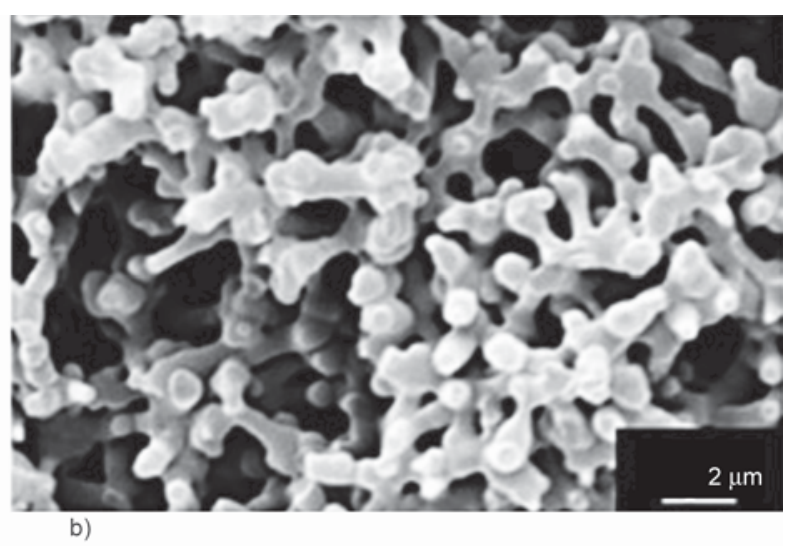

Figure 11. SEM micrographs of epoxy samples after extraction of different amounts of electrolyte (EMIm-TFSI + LiTFSI): (a) $60 \mathrm{wt} \%$; (b) $70 \mathrm{wt} \%$ [67].

Table 3. General overview of IL influence on epoxy resins.

\begin{tabular}{|c|c|c|c|}
\hline Base polymer & Ionic liquid & Results & Ref. \\
\hline \multirow{12}{*}{ DGEBA } & {$[\mathrm{DiOIm}][\mathrm{I}]$} & crosslinking promotion, plasticizing effect & [42] \\
\hline & $\begin{array}{l}{[\mathrm{apbIm}]\left[\mathrm{NTf}_{2}\right]} \\
{[\mathrm{N} 4444][\text { Leu }]}\end{array}$ & catalytic effect, conductivity improvement & [40] \\
\hline & $\begin{array}{l}{[\text { DodIm }][\mathrm{I}]} \\
{[\text { OdPyr }][\mathrm{I}]} \\
{[\text { OdTPP }][\mathrm{I}]} \\
{[\text { OdTPP }]\left[\mathrm{PF}_{6}\right]}\end{array}$ & $\begin{array}{l}\text { accelerating effect, plasticizing effect, stiffness improve- } \\
\text { ment }\end{array}$ & [43] \\
\hline & CYPHOS $^{\circledR}$ IL104 & catalytic effect, thermal stability improvement & [44] \\
\hline & $\begin{array}{l}{[\mathrm{BMIm}]\left[\mathrm{N}(\mathrm{CN})_{2}\right]} \\
{[\mathrm{BMIm}]\left[\mathrm{BF}_{4}\right]} \\
{[\mathrm{DMIm}]\left[\mathrm{N}(\mathrm{CN})_{2}\right]} \\
{[\mathrm{DMIm}]\left[\mathrm{BF}_{4}\right]} \\
{[\mathrm{DMIm}][\mathrm{Cl}]}\end{array}$ & catalytic effect & [46] \\
\hline & {$[\mathrm{EMIm}]\left[\mathrm{N}(\mathrm{CN})_{2}\right]$} & thermally latent curing agent & [47] \\
\hline & $\begin{array}{l}\text { CYPHOS }^{\circledR} \text { IL104 } \\
\text { CYPHOS }^{\circledR} \text { IL169 }\end{array}$ & $\begin{array}{l}\text { homopolymerization promotion, hydrophobicity and ther- } \\
\text { mal stability improvement }\end{array}$ & [57] \\
\hline & CYPHOS $^{\circledR}$ IL104 & $\begin{array}{l}\text { curing agent for the epoxy prepolymer, excellent dispersant } \\
\text { aid for the MWCNT }\end{array}$ & [58] \\
\hline & $\begin{array}{l}{[\text { OdTPP }][\mathrm{I}]} \\
{[\text { DodIm }][\mathrm{I}]}\end{array}$ & $\begin{array}{l}\text { accelerating effect, phase separation, tensile properties and } \\
\text { conductivity improvement }\end{array}$ & [63] \\
\hline & CYPHOS $^{\circledR}$ IL105 & catalytic effect, phase separation generation & [66] \\
\hline & {$[\mathrm{DMIm}][\mathrm{Br}]$} & $\begin{array}{l}\text { solid and flexible electrolyte with good thermal stability } \\
\text { below } 180^{\circ} \mathrm{C}\end{array}$ & [69] \\
\hline & {$[\mathrm{OMIm}]\left[\mathrm{BF}_{4}\right]$} & $\begin{array}{l}\text { accelerating effect, lower hardness, viscoelastic recovery } \\
\text { and healing ability of damaged surface with time }\end{array}$ & $\begin{array}{l}{[70],} \\
{[72],} \\
{[74]}\end{array}$ \\
\hline DGEBA, TEPA & $\begin{array}{l}\text { [EMIm][TFSI] } \\
{[\mathrm{HMIm}][\mathrm{TFSI}]} \\
{[\mathrm{BMIm}][\mathrm{TFSI}]}\end{array}$ & $\begin{array}{l}\text { microphase separation, morphology and properties depend- } \\
\text { ence on IL content }\end{array}$ & [64] \\
\hline Bisphenol A epichlorhydrin & {$[\mathrm{OMIm}]\left[\mathrm{BF}_{4}\right]$} & self-healing under ambient conditions & [71] \\
\hline $\begin{array}{l}\text { EGGE PPOGE } \\
\text { PEGGE } \\
\text { PPOBA } \\
\text { PEGBA }\end{array}$ & [GTMA][TFSI] & high thermal stability, flexibility and good ionic conductivity & {$[65]$} \\
\hline \multirow{2}{*}{$\begin{array}{l}\text { Bisphenol A-based } \\
\text { Epidian } 6\end{array}$} & {$[\mathrm{BMIm}][\mathrm{SCN}]$} & catalytic activity & [48] \\
\hline & $\begin{array}{l}{[\mathrm{EMIm}]\left[\mathrm{N}(\mathrm{CN})_{2}\right]} \\
{[\mathrm{THTDP}][\mathrm{N}(\mathrm{CN}) 2]}\end{array}$ & catalytic effect & [49] \\
\hline $\begin{array}{l}\text { MVR }^{\circledR} 444 \\
\text { MTM }^{\circledR} 57 \\
\text { VTM }^{\circledR} 266\end{array}$ & {$[\mathrm{EMIm}][\mathrm{TFSI}]$} & ionic conductivity improvement & [67] \\
\hline
\end{tabular}


In conclusion, ILs constitute excellent multifunctional agents that are sustainable for developing new high-performance epoxy materials (Table 3 ).

\subsection{Ionic liquids in cyanate ester resins (CERs)}

To the best of our knowledge, only a few reports on the IL utilization for designing CER systems have been published so far [87-89]. Throckmorton and Palmese in 2016 firstly reported [87] a new way to accelerate CER polycyclotrimerization by using dicyanamide-containing RTILs ([DCNA $]^{-}$) as a new catalytic system alternative to conventional catalysts normally based on metal acetylacetonates and nonyl phenol. Novel ionic thermosetting polymers, i.e. polycyanurates containing the ILs incorporated chemically directly into the triazine network, were thus synthesized. The catalytic effect was found in a number of dicyanamide-containing ILs with diverse cations, namely 1-ethyl-3-methyl imidazolium, 1-(3-cyanopropyl)-3-methyl imidazolium, 1-(2-hydroxyethyl)3-methylimidazolium, 1-butyl-1-methyl-pyrrolidinium, and 1-butyl-3-methyl pyridinium. For comparison, the non-dicyanamide RTIL, 1-ethyl-3-methyl imidazolium tetrafluoroborate $\left([\mathrm{BMIm}]\left[\mathrm{BF}_{4}\right]\right)$ was checked as a catalyst for CER polycyclotrimerization. It was found that the reaction kick off tempera-

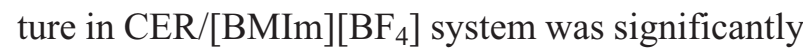
higher than that for the $[\mathrm{DCNA}]^{-}$containing ILs. The following conclusions could be done on the basis of these results: (i) RTILs of varying structures and concentrations accelerated curing of CERs; (ii) $[\mathrm{DCNA}]^{-}$ILs were incorporated directly into the triazine network; (iii) plasticization effect was fixed depending on RTIL content $(0.5-10 \mathrm{wt} \%)$ due to decrease in cross-linking density (nearly $100^{\circ} \mathrm{C}$ decrease in $T_{\mathrm{g}}$ at $10 \mathrm{wt} \%$ IL loading). Finally, the ionic thermoset structure presented a cured resin with ionically bound species that provided an excellent subject for future research in ionomers and nanocomposites.

Although the reaction mechanism of CER curing in the presence of [DCNA]-based ILs was investigated thoroughly, the mechanism of catalysis by non-dicyanamide RTILs was not discussed. Based on the studies mentioned above, one can conclude that in order to develop novel CER-based materials with new properties, research on the application of other ILs should be continued.

These results prompted us to investigate the effect of other non-dicyanamide ILs on the kinetics of the

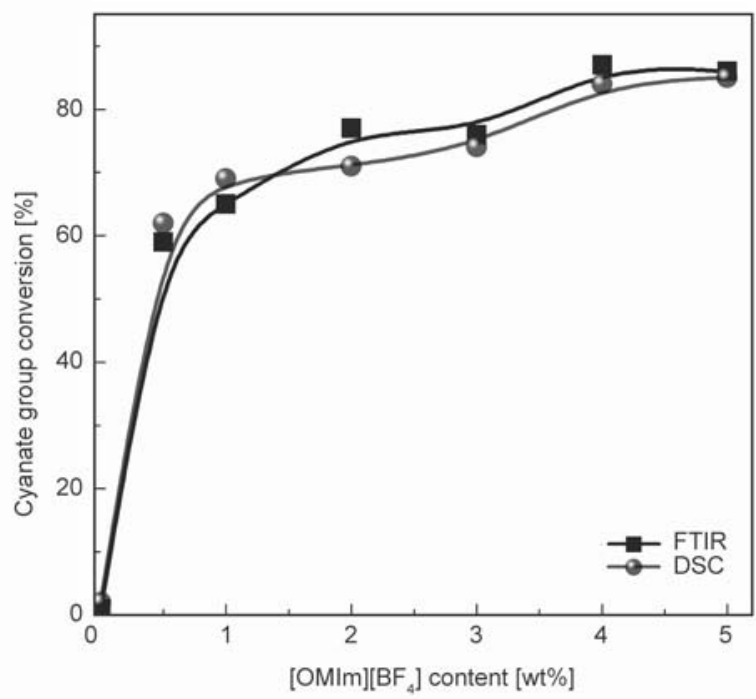

Figure 12. Concentration dependence of CER monomer in the $\mathrm{CER} /[\mathrm{OMIm}]\left[\mathrm{BF}_{4}\right]$ samples at heating at $150^{\circ} \mathrm{C}$ for $6 \mathrm{~h}$

CER system [88]. We found that small additions (0.5$5.0 \mathrm{wt} \%$ ) of 1-octyl-3-methylimidazolium tetrafluoroborate $\left([\mathrm{OMIm}]\left[\mathrm{BF}_{4}\right]\right)$ significantly accelerated the kinetics of CER polycyclotrimerization. For samples containing $[\mathrm{OMIm}]\left[\mathrm{BF}_{4}\right]$, polycyclotrimerization of monomer took place even at the heating stage at $150^{\circ} \mathrm{C}$, while for pure monomer polycyclotrimerization practically did not occur (Figure 12). A reaction mechanism was newly proposed via the involvement of a $\left.[\mathrm{CN}]^{\delta+}---\mathrm{OMIm}\right]^{\delta-}$ complex as a key intermediate (Figure 13). We assume that such catalytic effect of imidazolium-based ILs would take place with any dicyanate monomer.

To the best of our knowledge until 2017, no systematic studies on using ILs as porogens for producing porous CER networks have been reported. In our recent research [89], 1-heptylpyridinium tetrafluoroborate IL ([HPyr $\left.]\left[\mathrm{BF}_{4}\right]\right)$ was chosen as a porogen for CER-based films. Complete IL removal was confirmed by determination of gel fraction contents, FTIR, ${ }^{1} \mathrm{H}$ NMR, and EDX spectroscopic analyses. Typical SEM images of CER films before extraction of $[\mathrm{HPyr}]\left[\mathrm{BF}_{4}\right]\left(\mathrm{CER}_{40}\right)$ and after extraction of the latter $\left(\mathrm{CER}_{40 \mathrm{ext}}\right)$ are presented in Figure 14. As it was

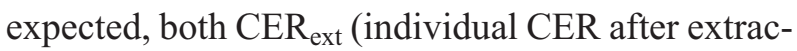
tion) and $\mathrm{CER}_{40}$ samples (Figure 14a and 14c, respectively) exhibited compact and non-porous structures, whereas $\mathrm{CER}_{20 \mathrm{ext}}$ and CER $40 \mathrm{ext}$ samples (CERs containing 20 and $40 \mathrm{wt} \%$ IL after extraction, Figure $14 \mathrm{~b}$ and $14 \mathrm{~d}$, respectively) displayed a nanoporous structure with pore diameters ranging from 25 to $170 \mathrm{~nm}$, depending on their CER/IL composition. SEM and 


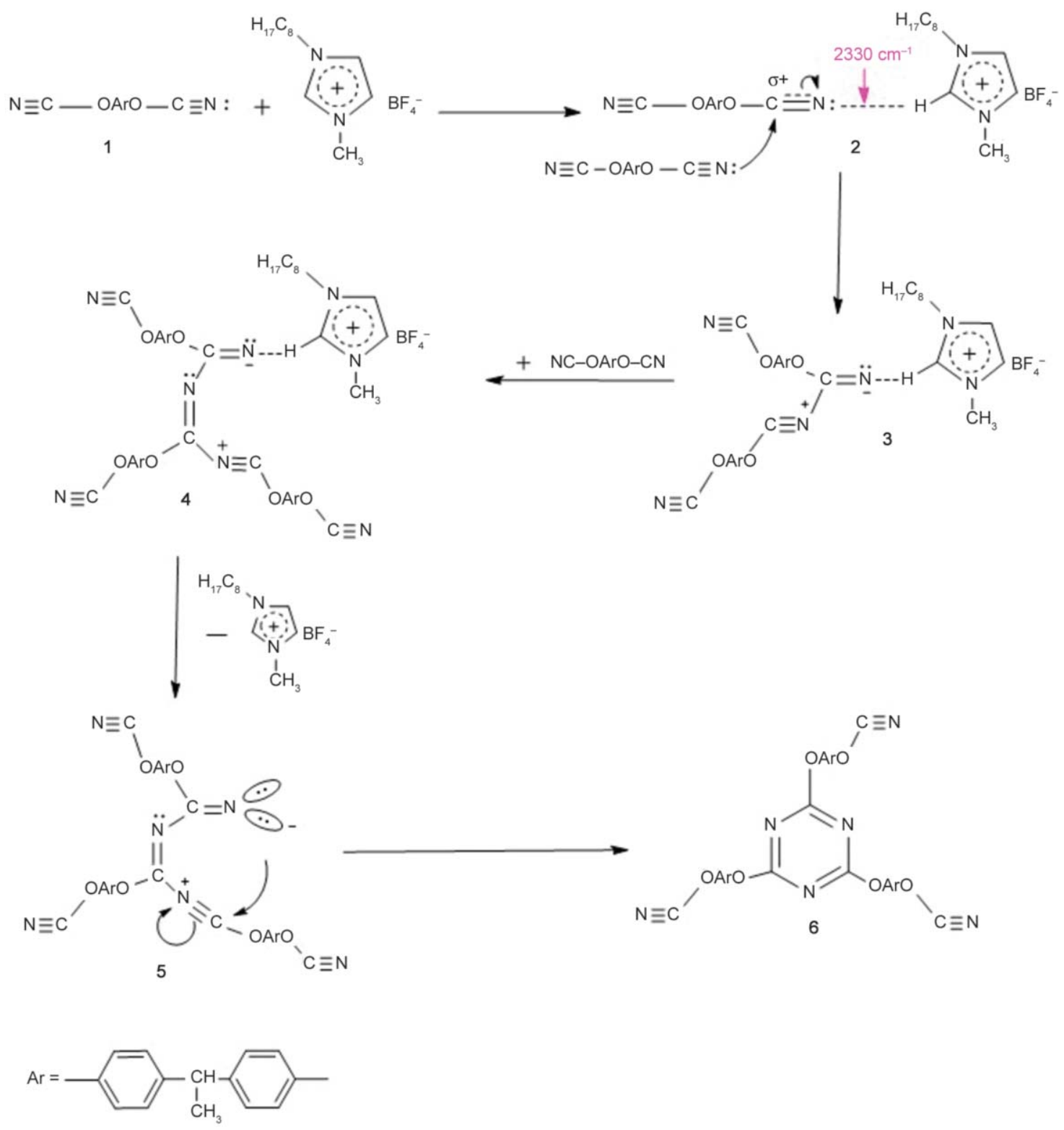

Figure 13. The mechanism proposed for the $[\mathrm{OMIm}]\left[\mathrm{BF}_{4}\right]$-catalyzed DCBE cyclotrimerization.

DSC-based thermoporometry were used as complementary techniques for nanopore characterization. Depending on the IL porogen content, the average pore diameter values were found in the range of 45$60 \mathrm{~nm}$ with pore size distributions of $\sim 20-180 \mathrm{~nm}$ (Figure 15). It is also noteworthy that an increase in the $[\mathrm{HPyr}]\left[\mathrm{BF}_{4}\right]$ content resulted in increasing pore diameters and broader pore size distributions. The TGA curves showed the high thermal stability of the nanoporous films obtained with an onset decomposition temperature near $300^{\circ} \mathrm{C}$. It should be stressed that the synthesis of CERs in the presence of IL was carried out without using any additional solvents or specific catalysts.

\section{Conclusions}

According to the best of our knowledge, up to now, no systematic study on the application of ionic liquids in thermosetting polymers, especially epoxy and cyanate ester resins have been reported. The present review aims at defining a new generation of thermally stable materials based on thermosets modified by ionic liquids (ILs). Among the wide range of potential applications of ILs, their use in the development of new thermoset-IL hybrid materials has been limited by modification of epoxy and cyanate ester resins. In fact, the studies on epoxy resin systems with ILs are quite extensive. In the reviewed studies, we have found that ILs can be effectively 


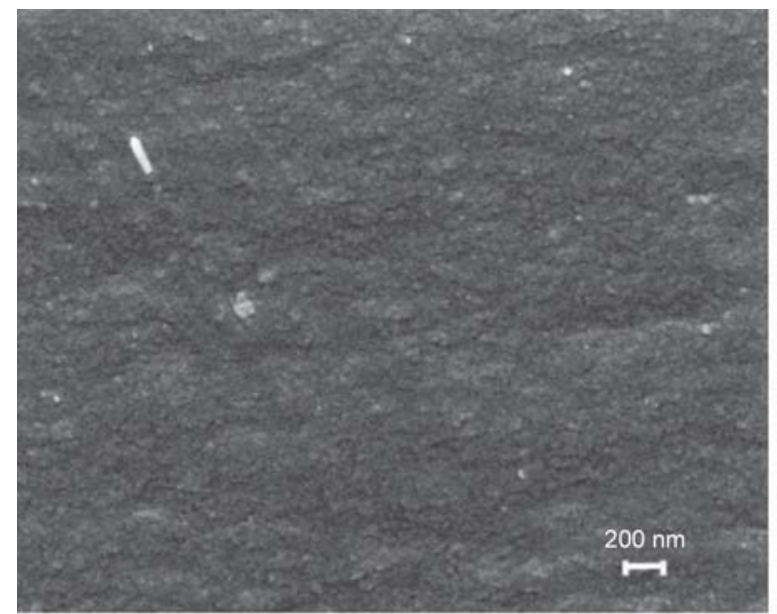

a)

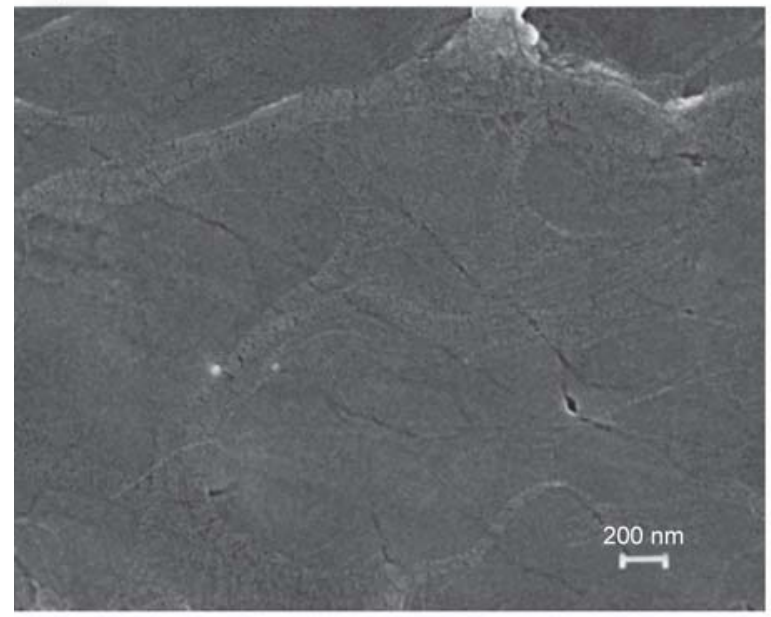

c)

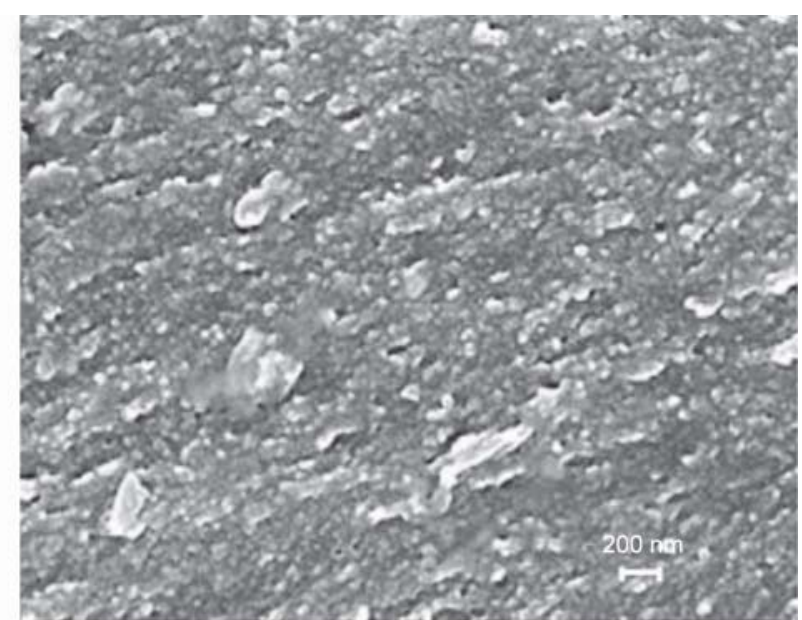

b)

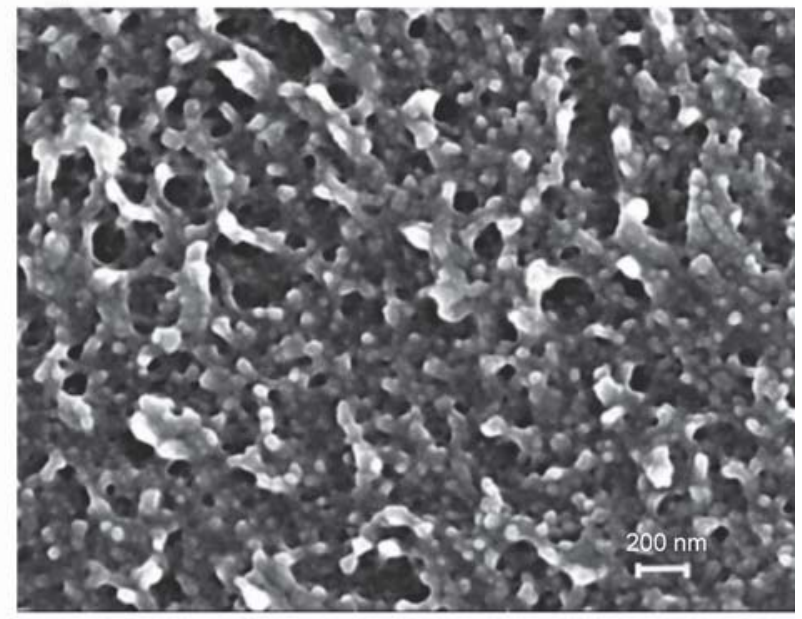

d)

Figure 14. Typical SEM micrographs of CER-based samples: (a) $\mathrm{CER}_{\text {ext }}$, (b) $\mathrm{CER}_{20 \mathrm{ext}}$, (c) $\mathrm{CER}_{40}$, (d) $\mathrm{CER}_{40 \mathrm{ext}}$.
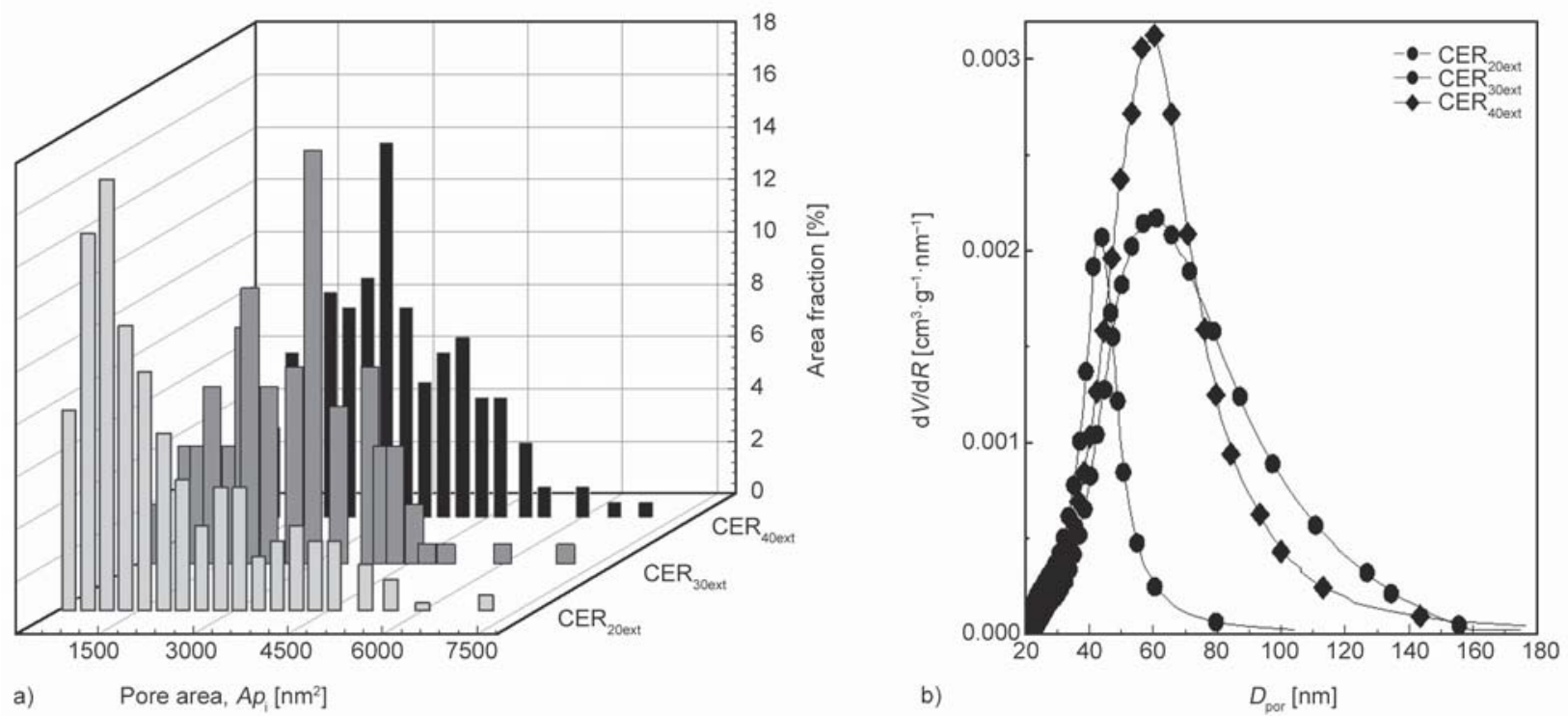

Figure 15. (a) Pore area distributions derived from SEM data for the nanoporous CER-based samples and (b) Pore size distribution profiles derived from DSC-thermoporometry.

used for epoxy resins as catalytic or/and crosslinking agents, plasticizers, lubricants, electrolytes or porogens thus providing a new route to the design of advanced materials. So far, imidazolium ILs have been more often applied in epoxy resin systems than other ones, however the reasons why one might be 
interested in a phosphonium ILs, even in industrial processes, include its availability and cost. It seems that epoxy resin systems could be improved by the selection of IL type and concentration as well as by the introduction of additives, e.g. nanoparticles, graphene or carbon nanotubes, in low loading to obtain high-performance materials. On the other side, the investigation of cyanate ester resins (CERs) is fairly limited in the literature and only few researchers have developed the use of ILs as catalysts and porogens. Despite these successes, using ILs still remains an exciting and emerging field of research. The influence of IL on the ductility, abrasion resistance, and self-repairing ability of epoxy resins has been well understood, however, self-healing ability of ILbased CER materials remains to be studied. It appears reasonable to expect (i) comprehension of IL organization within the polymer network; (ii) network-IL interactions; (iii) suitable functionalization of the ILs for reactive modification of thermosets; (iv) molecular mechanisms of IL lubrication; (v) separation/sorption properties of IL-based thermosetting networks before and after extraction for membrane technologies; (vi) compatibilizing effect of ILs in the hydrophobic polymer networks filled with hydrophilic fillers. Through numerous attempts made so far, the prospect of ILs as electrolyte salts for engineering of highly conducting polymer electrolytes and characterizing their ion transport behaviour left out of consideration and further studies are still needed. The IL-based thermosetting materials could be good candidates for use in any application, in which high conductivity combined with high thermal stability and non-volatility are required.

\section{Acknowledgements}

The authors gratefully the National Academy of Sciences of Ukraine and the 'Centre National de la Recherche Scientifique' of France for partial financial support (LIA project). They are also indebted to the Campus France for the Eiffel grant No. 870769C provided to A. Vashchuk.

\section{References}

[1] Huddleston J. G., Visser A. E., Reichert W. M., Willauer H. D., Broker G. A., Rogers R. D.: Characterization and comparison of hydrophilic and hydrophobic room temperature ionic liquids incorporating the imidazolium cation. Green Chemistry, 3, 156-164 (2001).

https://doi.org/10.1039/b103275p
[2] Li Y., Zhang C., Zhou Y., Dong Y., Chen W.: Novel multi-responsive polymer materials: When ionic liquids step in. European Polymer Journal, 69, 441-448 (2015). https://doi.org/10.1016/j.eurpolymj.2015.05.023

[3] Lu J., Yan F., Texter J.: Advanced applications of ionic liquids in polymer science. Progress in Polymer Science, 34, 431-448 (2009).

https://doi.org/10.1016/j.progpolymsci.2008.12.001

[4] Welton T.: Ionic liquids in catalysis. Coordination Chemistry Reviews, 248, 2459-2477 (2004).

https://doi.org/10.1016/j.ccr.2004.04.015

[5] Winterton N.: Solubilization of polymers by ionic liquids. Journal of Materials Chemistry, 16, 4281-4293 (2006). https://doi.org/10.1039/B610143G

[6] Snedden P., Cooper A. I., Scott K., Winterton N.: Crosslinked polymer-ionic liquid composite materials. Macromolecules, 36, 4549-4556 (2003).

https://doi.org/10.1021/ma021710n

[7] Klingshirn M. A., Spear S. K., Subramanian R., Holbrey J. D., Huddleston J. G., Rogers R. D. J.: Gelation of ionic liquids using a cross-linked poly(ethylene glycol) gel matrix. Chemistry of Materials, 16, 3091-3097 (2004).

https://doi.org/10.1021/cm0351792

[8] Susan M. A. B. H., Kaneko T., Noda A., Watanabe M. J.: Ion gels prepared by in situ radical polymerization of vinyl monomers in an ionic liquid and their characterization as polymer electrolytes. Journal of the American Chemical Society, 127, 4976-4983 (2005).

https://doi.org/10.1021/ja045155b

[9] Nakajima H., Ohno H.: Preparation of thermally stable polymer electrolytes from imidazolium-type ionic liquid derivatives. Polymer, 46, 11499-11504 (2005).

https://doi.org/10.1016/j.polymer.2005.10.005

[10] Néouze M-A., le Bideau J., Gaveau P., Bellayer S., Vioux A.: Ionogels, new materials arising from the confinement of ionic liquids within silica-derived networks. Chemistry of Materials, 18, 3931-3936 (2006). https://doi.org/10.1021/cm060656c

[11] Tigelaar D. M., Meador M. A. B., Bennett W. R.: Composite electrolytes for lithium batteries: Ionic liquids in APTES cross-linked polymers. Macromolecules, 40, 4159-4164 (2007). https://doi.org/10.1021/ma062804q

[12] Xie Y., Zhang Z., Jian T., He J., Han B., Wu T., Ding $\mathrm{K}$.: $\mathrm{CO}_{2}$ cycloaddition reactions catalyzed by an ionic liquid grafted onto a highly cross linked polymer matrix. Angewandte Chemie International Edition, 46, 7255-7258 (2007).

https://doi.org/10.1002/anie.200701467

[13] Walden P.: Molecular weights and electrical conductivity of several fused salts. Bulletin of the Imperial Academy of Sciences (Saint Petersburg), 1800, 405-422 (1914). 
[14] Chum H. L., Koch V. R., Miller L. L., Osteryoung R. A.: Electrochemical scrutiny of organometallic iron complexes and hexamethylbenzene in a room temperature molten salt. Journal of the American Chemical Society, 97, 3264-3267 (1975).

https://doi.org/10.1021/ja00844a081

[15] Wilkes J. S., Levisky J. A., Wilson R. A., Hussey C. L.: Dialkylimidazolium chloroaluminate melts: A new class of room-temperature ionic liquids for electrochemistry, spectroscopy, and synthesis. Inorganic Chemistry, 21, 1263-1264 (1982). https://doi.org/10.1021/ic00133a078

[16] Wilkes J. S., Zaworotko M. J.: Air and water stable 1ethyl-3-methylimidazolium based ionic liquids. Journal of the Chemical Society, Chemical Communications, 0, 965-967 (1992). https://doi.org/10.1039/C39920000965

[17] Welton T.: Room-temperature ionic liquids. Solvents for synthesis and catalysis. Chemical Reviews, 99, 2071-2083 (1999).

https://doi.org/10.1021/cr980032t

[18] Hallett J. P., Welton T.: Room-temperature ionic liquids: Solvents for synthesis and catalysis. 2. Chemical Reviews, 111, 3508-3576 (2011). https://doi.org/10.1021/cr1003248

[19] Marsh K. N., Boxall J. A., Lichtenthaler R.: Room temperature ionic liquids and their mixtures - A review. Fluid Phase Equilibria, 219, 93-98 (2004). https://doi.org/10.1016/j.fluid.2004.02.003

[20] Plechkova N. V., Seddon K. R.: Applications of ionic liquids in the chemical industry. Chemical Society Reviews, 37, 123-150 (2008). https://doi.org/10.1039/b006677j

[21] Rogers R. D., Seddon K. R.: Ionic liquids--Solvents of the future? Science, 302, 792-793 (2003). https://doi.org/10.1126/science.1090313

[22] Armand M., Endres F., MacFarlane D. R., Ohno H., Scrosati B.: Ionic-liquid materials for the electrochemical challenges of the future. Nature Materials, 8, 621629 (2009). https://doi.org/10.1038/NMAT2448

[23] Livi S., Duchet-Rumeau J., Gérard J-F., Pham T. N.: Polymers and ionic liquids: A successful wedding. Macromolecular Chemistry and Physics, 216, 359-368 (2015). https://doi.org/10.1002/macp.201400425

[24] Mecerreyes D.: Applications of ionic liquids in polymer science and technology. Springer, Berlin (2015). https://doi.org/10.1007/978-3-662-44903-5

[25] Gaune-Escard M., Seddon K. R.: Molten salts and ionic liquids: Never the twain? Wiley, Hoboken (2010).

[26] Wilkes J. S.: A short history of ionic liquids - From molten salts to neoteric solvents. Green Chemistry, 4, 73-80 (2002).

https://doi.org/10.1039/B110838G
[27] Dupont J.: From molten salts to ionic liquids: A 'nano' journey. Accounts of Chemical Research, 44, 12231231 (2011).

https://doi.org/10.1021/ar2000937

[28] Gore R. G., Gathergood N.: Safer and greener catalysts - Design of high performance, biodegradable and low toxicity ionic liquids. in 'Ionic liquids - New aspects for the future' (ed.: Kadokawa J.) InTech, Rijeka 499535 (2013).

https://doi.org/10.5772/51879

[29] Sowmiah S., Srinivasadesikan V., Tseng M-C., Chu Y-H.: On the chemical stabilities of ionic liquids. Molecules, 14, 3780-3813 (2009).

https://doi.org/10.3390/molecules 14093780

[30] Pringle J. M., Golding J., Forsyth C. M., Deacon G. B., Forsyth M., MacFarlane D. R. J.: Physical trends and structural features in organic salts of the thiocyanate anion. Journal of Materials Chemistry, 12, 3475-3480 (2002).

https://doi.org/10.1039/B208372H

[31] Kulkarni P. S., Branco L. C., Crespo J. G., Nunes M. C., Raymondo A., Alfonso C. A. M.: Comparison of physicochemical properties of new ionic liquids based on imidazolium, quaternary ammonium, and guanidinium cations. Chemistry A European Journal, 13, 84788488 (2007). https://doi.org/10.1002/chem.200700965

[32] Maton C., De Vos N., Stevens C. V.: Ionic liquid thermal stabilities: Decomposition mechanisms and analysis tools. Chemical Society Reviews, 42, 5963-5977 (2013). https://doi.org/10.1039/C3CS60071H

[33] Seddon K. R., Stark A., Torres M-J.: Influence of chloride, water, and organic solvents on the physical properties of ionic liquids. Pure and Applied Chemistry, 72, 2275-2287 (2000).

https://doi.org/10.1351/pac200072122275

[34] Angell C. A., Byrne N., Belieres J-P.: Parallel developments in aprotic and protic ionic liquids: Physical chemistry and applications. Accounts of Chemical Research, 40, 1228-1236 (2007). https://doi.org/10.1021/ar7001842

[35] Tsuzuki S., Shinoda W., Miran M. S., Kinoshita H., Yasuda T., Watanabe M.: Interactions in ion pairs of protic ionic liquids: Comparison with aprotic ionic liquids. Journal of Chemical Physics, 139, 174504/1-174504/9 (2013).

https://doi.org/10.1063/1.4827519

[36] Greaves T. L., Drummond C. J.: Protic ionic liquids: Properties and applications. Chemical Reviews, 108, 206-237 (2008).

https://doi.org/10.1021/cr068040u

[37] Belieres J-P., Angell A. C.: Protic ionic liquids: Preparation, characterization, and proton free energy level representation. The Journal of Physical Chemistry B, 111, 4926-4937 (2007). https://doi.org/10.1021/jp067589u 
[38] Luo H., Huang J-F., Dai S.: Studies on thermal properties of selected aprotic and protic ionic liquids. Separation Science and Technology, 43, 2473-2488 (2008). https://doi.org/10.1080/01496390802151922

[39] Hong K., Zhang H., Mays J. W., Visser A. E., Brazel C. S., Holbrey J. D., Reichert W. M., Rogers R. D.: Conventional free radical polymerization in room temperature ionic liquids: A green approach to commodity polymers with practical advantages. Chemical Communications, 13, 1368-1369 (2002).

https://doi.org/10.1039/B204319J

[40] Maksym P., Tarnacka M., Dzienia A., Matuszek K., Chrobok A., Kaminski K., Paluch M.: Enhanced polymerization rate and conductivity of ionic liquid-based epoxy resin. Macromolecules, 50, 3262-3272 (2017). https://doi.org/10.1021/acs.macromol.6b02749

[41] Kowalczyk K., Spychaj T.: Ionic liquids as convenient latent hardeners of epoxy resins. Polimery, 48, 833-835 (2003).

[42] Soares B. G., Livi S., Duchet-Rumeau J., Gérard J-F.: Synthesis and characterization of epoxy/MCDEA networks modified with imidazolium based ionic liquids. Macromolecular Materials and Engineering, 296, 826834 (2011).

https://doi.org/10.1002/mame.201000388

[43] Soares B. G., Livi S., Duchet-Rumeau J., Gérard J. F.: Preparation of epoxy/MCDEA networks modified with ionic liquids. Polymer, 53, 60-66 (2012).

https://doi.org/10.1016/j.polymer.2011.11.043

[44] Silva A. A., Livi S., Netto D. B., Soares B. G., Duchet J., Gérard J-F.: New epoxy systems based on ionic liquid. Polymer, 54, 2123-2129 (2013).

https://doi.org/10.1016/j.polymer.2013.02.021

[45] Palmese G. R., Rahmathullah M. A. M., Jeyarajasingam A.: Room temperature ionic liquids and ionic liquid epoxy adducts as initiators for epoxy systems. WO Patent 2011142855 A2 (2012).

[46] Mąka H., Spychaj T., Pilawka R.: Epoxy resin/ionic liquid systems: The influence of imidazolium cation size and anion type on reactivity and thermomechanical properties. Industrial and Engineering Chemistry Research, 51, 5197-5206 (2012).

https://doi.org/10.1021/ie202321j

[47] Rahmathullah A. M., Jeyarajasingam A., Merritt B., Van Landingham M., McKnight S. H., Palmese G. R.: Room temperature ionic liquids as thermally latent initiators for polymerization of epoxy resins. Macromolecules, 42, 3219-3221 (2009).

https://doi.org/10.1021/ma802669k

[48] Mąka H., Spychaj T., Kowalczyk K.: Imidazolium and deep eutectic ionic liquids as epoxy resin crosslinkers and graphite nanoplatelets dispersants. Journal of Applied Polymer Science, 131, 40401/1-40401/7 (2014). https://doi.org/10.1002/APP.40401
[49] Mąka H., Spychaj T., Zenker M.: High performance epoxy composites cured with ionic liquids. Journal of Industrial and Engineering Chemistry, 31, 192-198 (2015). https://doi.org/10.1016/j.jiec.2015.06.023

[50] Mąka H., Spychaj T., Pilawka R.: Epoxy resin/phosphonium ionic liquid/carbon nanofiller systems: chemorheology and properties. Express Polymer Letters, 8, 723-732 (2014).

https://doi.org/10.3144/expresspolymlett.2014.75

[51] Liebner F., Patel I., Ebner G., Becker E., Horix M., Potthast A., Rosenau T.: Thermal aging of 1-alkyl-3-methylimidazolium ionic liquids and its effect on dissolved cellulose. Holzforschung, 64, 161-166 (2010). https://doi.org/10.1515/hf.2010.033

[52] Farkas A., Strohm P. F.: Imidazole catalysis in the curing of epoxy resins. Journal of Applied Polymer Science, 12, 159-168 (1968).

https://doi.org/10.1002/app.1968.070120115

[53] Ghaemy M., Sadjady S.: Kinetic analysis of curing behavior of diglycidyl ether of bisphenol A with imidazoles using differential scanning calorimetry techniques. Journal of Applied Polymer Science, 100, 2634-2641 (2006).

https://doi.org/10.1002/app.22716

[54] Meng F., Zhang W., Zheng S.: Epoxy resin cured with poly(4-vinyl pyridine). Journal of Materials Science, 40, 6367-6373 (2005).

https://doi.org/10.1007/s10853-005-1732-2

[55] Ricciardi F., Joullié M. M., Romanchick W. A., Griscavage A. A.: Mechanism of imidazole catalysis in the curing of epoxy resins. Journal of Polymer Science: Polymer Letters Edition, 20, 127-133 (1982). https://doi.org/10.1002/pol.1982.130200209

[56] Xue G., Ishida H., Koenig J. L.: Polymerization of styrene oxide with pyridine. Macromolecular Rapid Communications, 7, 37-41 (1986). https://doi.org/10.1002/marc.1986.030070107

[57] Nguyen T. K. L., Livi S., Pruvost S., Soares B. G., Duchet-Rumeau J.: Ionic liquids as reactive additives for the preparation and modification of epoxy networks. Journal of Polymer Science Part A: Polymer Chemistry, 52, 3463-3471 (2014). https://doi.org/10.1002/pola.27420

[58] Soares B. G., Riany N., Silva A. A., Barra G. M. O., Livi S.: Dual-role of phosphonium - Based ionic liquid in epoxy/MWCNT systems: Electric, rheological behavior and electromagnetic interference shielding effectiveness. European Polymer Journal, 84, 77-88 (2016). https://doi.org/10.1016/j.eurpolymj.2016.09.016

[59] Nguyen T. K. L., Livi S., Soares B. G., Pruvost S., Duchet-Rumeau J., Gérard J-F.: Ionic liquids: A new route for the design of epoxy networks. ACS Sustainable Chemistry and Engineering, 4, 481-490 (2016). https://doi.org/10.1021/acssuschemeng.5b00953 
[60] Ogihara W., Washiro S., Nakajima H., Ohno H.: Effect of cation structure on the electrochemical and thermal properties of ion conductive polymers obtained from polymerizable ionic liquids. Electrochimica Acta, 51, 2614-2649 (2006).

https://doi.org/10.1016/j.electacta.2005.07.043

[61] Ohno H., Yoshizawa M., Ogihara W.: Development of new class of ion conductive polymers based on ionic liquids. Electrochimica Acta, 50, 255-261 (2004).

https://doi.org/10.1016/j.electacta.2004.01.091

[62] Washiro S., Yoshizawa M., Nakajima H., Ohno H.: Highly ion conductive flexible films composed of network polymers based on polymerizable ionic liquids. Polymer, 45, 1577-1582 (2004).

https://doi.org/10.1016/j.polymer.2004.01.003

[63] Soares B. G., Silva A. A., Livi S., Duchet-Rumeau J., Gerard J-F.: New epoxy/Jeffamine networks modified with ionic liquids. Journal of Applied Polymer Science, 131, 39834/1-39834/6 (2014).

https://doi.org/10.1002/APP.39834

[64] Matsumoto K., Endo T.: Confinement of ionic liquid by networked polymers based on multifunctional epoxy resins. Macromolecules, 41, 6981-6986 (2008). https://doi.org/10.1021/ma801293j

[65] Matsumoto K., Endo T.: Synthesis of ion conductive networked polymers based on an ionic liquid epoxide having a quaternary ammonium salt structure. Macromolecules, 42, 4580-4584 (2009).

https://doi.org/10.1021/ma900508q

[66] Livi S., Silva A. A., Thimont Y., Nguyen T. K. L., Soares B. G., Gérard J-F., Duchet-Rumeau J.: Nanostructured thermosets from ionic liquid building blockepoxy prepolymer mixtures. RSC Advances, 4, 28099 28106 (2014).

https://doi.org/10.1039/c4ra03643c

[67] Shirshova N., Bismarck A., Carreyette S., Fontana Q. P. V., Greenhalgh E. S., Jacobsson P., Johansson P., Marczewski M. J., Kalinka G., Kucernak A. R. J., Scheers J., Shaffer M. S. P., Steinke J. H. G., Wienrich M.: Structural supercapacitor electrolytes based on bicontinuous ionic liquid-epoxy resin systems. Journal of Materials Chemistry A, 1, 15300-15309 (2013). https://doi.org/10.1039/c3ta13163g

[68] Soares B. G., Silva A. A., Pereira J., Livi S.: Preparation of epoxy/Jeffamine networks modified with phosphonium based ionic liquids. Macromolecular Materials and Engineering, 300, 312-319 (2015).

https://doi.org/10.1002/mame.201400293

[69] da Silva L. C. O., Soares B. G.: New all solid state polymer electrolyte based on epoxy resin and ionic liquid for high temperature applications. Journal of Applied Polymer Science, 135, 45838/1-45838/8 (2017). https://doi.org/10.1002/app.45838

[70] Sanes J., Carrión-Vilches F-J., Bermúdez M. D.: New epoxy-ionic liquid dispersions. Room temperature ionic liquid as lubricant of epoxy resin-stainless steel contacts. e-Polymers, no.005 (2007).

https://doi.org/10.1515/epoly.2007.7.1.48
[71] Saurín N., Sanes J., Bermúdez M. D.: Self-healing of abrasion damage in epoxy resin-ionic liquid nanocomposites. Tribology Letters, 58, 4/1-4/9 (2015). https://doi.org/10.1007/s11249-015-0490-9

[72] Saurín N., Sanes J., Carrión F. J., Bermúdez M. D.: Self-healing of abrasion damage on epoxy resin controlled by ionic liquid. RSC Advances, 6, 37258-37264 (2016). https://doi.org/10.1039/c6ra05503f

[73] Sanes J., Carrión F. J., Bermúdez M. D.: Effect of the addition of room temperature ionic liquid and $\mathrm{ZnO}$ nanoparticles on the wear and scratch resistance of epoxy resin. Wear, 268, 1295-1302 (2010). https://doi.org/10.1016/j.wear.2010.01.024

[74] Saurín N., Sanes J., Bermúdez M. D.: Effect of graphene and ionic liquid additives on the tribological performance of epoxy resin. Tribology Letters, 56, 133-142 (2014). https://doi.org/10.1007/s11249-014-0392-2

[75] Sanes J., Saurín N., Carrión F. J., Ojados G., Bermúdez M. D.: Synergy between single-walled carbon nanotubes and ionic liquid in epoxy resin nanocomposites. Composites Part B: Engineering, 105, 149-159 (2016). https://doi.org/10.1016/j.compositesb.2016.08.044

[76] Avilés M. D., Saurín N., Espinosa T., Sanes J., AriasPardilla J., Carrión F. J., Bermúdez M. D.: Self-lubricating, wear resistant protic ionic liquid-epoxy resin. Express Polymer Letters, 11, 219-229 (2017). https://doi.org/10.3144/expresspolymlett.2017.23

[77] Hameed N., Salim N. V., Walsh T. R., Wiggins J. S., Ajayan P. M., Fox B. L.: Ductile thermoset polymers via controlling network flexibility. Chemical Communications, 51, 9903-9906 (2015). https://doi.org/10.1039/C4CC10192H

[78] van Krevelen D. W.: Properties of polymers. Elsevier, Amsterdam (2009).

[79] Mohamed M. H., Wilson L. D.: Porous copolymer resins: Tuning pore structure and surface area with non reactive porogens. Nanomaterials, 2, 163-186 (2012). https://doi.org/10.3390/nano2020163

[80] Okay O.: Macroporous copolymer networks. Progress in Polymer Science, 25, 711-779 (2000). https://doi.org/10.1016/S0079-6700(00)00015-0

[81] Mane S.: Effect of porogens (type and amount) on polymer porosity: A review. Canadian Chemical Transactions, 4, 210-225 (2016).

https://doi.org/10.13179/canchemtrans.2016.04.02.0304

[82] Kubisa P.: Ionic liquids in the synthesis and modification of polymers. Journal of Polymer Science Part A: Polymer Chemistry, 43, 4675-4683 (2005). https://doi.org/10.1002/pola.20971

[83] Snedden P., Cooper A. I., Khimyak Y. Z., Scott K., Winterton N.: Cross-linked polymers in ionic liquids: Ionic liquids as porogens. in 'Ionic liquids in polymer systems' (ed.: Brazel C. S., Rogers R. D.) American Chemical Society, Washington, 133-147 (2005). https://doi.org/10.1021/bk-2005-0913.ch009 
[84] Booker K., Holdsworth C. I., Doherty C. M., Hill A. J., Bowyer M. C., McCluskey A.: Ionic liquids as porogens for molecularly imprinted polymers: Propranolol, a model study. Organic and Biomolecular Chemistry, 12, 7201-7210 (2014). https://doi.org/10.1039/C4OB00547C

[85] Singco B., Lin C-L., Cheng Y-J., Shih Y-H., Huang $\mathrm{H}-\mathrm{Y}$.: Ionic liquids as porogens in the microwave-assisted synthesis of methacrylate monoliths for chromatographic application. Analytica Chimica Acta, 746, 123-133 (2012).

https://doi.org/10.1016/j.aca.2012.08.034

[86] Hasegawa G., Kanamori K., Nakanishi K., Yamago S.: Fabrication of highly crosslinked methacrylate-based polymer monoliths with well-defined macropores via living radical polymerization. Polymer, 52, 4644-4647 (2011).

https://doi.org/10.1016/j.polymer.2011.08.028
[87] Throckmorton J., Palmese G.: Acceleration of cyanate ester trimerization by dicyanamide RTILs. Polymer, 91, 7-13 (2016).

https://doi.org/10.1016/j.polymer.2016.03.019

[88] Fainleib A., Grigoryeva O., Starostenko O., Vashchuk A., Rogalsky S., Grande D.: Acceleration effect of ionic liquids on polycyclotrimerization of dicyanate esters. Express Polymer Letters, 10, 722-729 (2016). https://doi.org/10.3144/expresspolymlett.2016.66

[89] Fainleib A., Vashchuk A., Starostenko O., Grigoryeva O., Rogalsky S., Nguyen T-T-T., Grande D.: Nanoporous polymer films of cyanate ester resins designed by using ionic liquids as porogens. Nanoscale Research Letters, 12, 126/1-126/9 (2017). https://doi.org/10.1186/s11671-017-1900-8 